\title{
Article \\ Osmium Nanoparticles-Polypropylene Hollow Fiber Membranes Applied in Redox Processes
}

\author{
Gheorghe Nechifor ${ }^{1}\left(\mathbb{D}\right.$, Florentina Mihaela Păncescu ${ }^{1}\left(\mathbb{D}\right.$, Alexandra Raluca Grosu ${ }^{1}\left(\mathbb{D}\right.$, Paul Constantin Albu ${ }^{2, *} \mathbb{0}$, \\ Ovidiu Oprea ${ }^{3}{ }^{\circledR}$, Szidonia-Katalin Tanczos ${ }^{4}$, Constantin Bungău ${ }^{5}$, Vlad-Alexandru Grosu ${ }^{6, *}{ }^{\mathbb{D}}$, Andreia Pîrțac ${ }^{1}$ \\ and Aurelia Cristina Nechifor ${ }^{1}$
}

Citation: Nechifor, G.; Păncescu, F.M.; Grosu, A.R.; Albu, P.C.; Oprea, O.; Tanczos, S.-K.; Bungău, C.; Grosu, V.-A.; Pîrțac, A.; Nechifor, A.C. Osmium Nanoparticles-

Polypropylene Hollow Fiber Membranes Applied in Redox Processes. Nanomaterials 2021, 11 , 2526. https://doi.org/10.3390/ nano11102526

Academic Editors: Angelina Angelova and Kamalesh K. Sirkar

Received: 20 July 2021

Accepted: 23 September 2021

Published: 27 September 2021

Publisher's Note: MDPI stays neutral with regard to jurisdictional claims in published maps and institutional affiliations.

Copyright: (c) 2021 by the authors. Licensee MDPI, Basel, Switzerland. This article is an open access article distributed under the terms and conditions of the Creative Commons Attribution (CC BY) license (https:// creativecommons.org/licenses/by/ $4.0 /)$.
1 Department of Analytical Chemistry and Environmental Engineering, University Politehnica of Bucharest, 011061 Bucharest, Romania; ghnechifor@gmail.com (G.N.); florynicorici@yahoo.com (F.M.P.); alexandra.raluca.miron@gmail.com (A.R.G.); andreia.pascu@yahoo.ro (A.P.); aureliacristinanechifor@gmail.com (A.C.N.)

2 National Institute for Research and Development in Physics and Nuclear Engineering, Radioisotopes and Radiation Metrology Department, 023465 Măgurele, Romania

3 Department of Inorganic Chemistry, Physical Chemistry and Electrochemistry, University Politehnica of Bucharest, 011061 Bucharest, Romania; ovidiu.oprea@upb.ro

4 Department of Bioengineering, Sapientia Hungarian University of Transylvania, 500104 Miercurea-Ciuc, Romania; tczszidonia@yahoo.com

5 Department of Engineering and Management, Faculty of Management and Technological Engineering, University of Oradea, 410087 Oradea, Romania; bungau@gmail.com

6 Department of Electronic Technology and Reliability, Faculty of Electronics, Telecommunications and Information Technology, University Politehnica of Bucharest, 061071 Bucharest, Romania

* Correspondence: paulalbu@gmail.com (P.C.A.); vlad.grosu@upb.ro (V.-A.G.)

Abstract: Composite membranes play a very important role in the separation, concentration, and purification processes, but especially in membrane reactors and membrane bioreactors. The development of composite membranes has gained momentum especially through the involvement of various nanoparticles, polymeric, oxide, or metal, that have contributed to increasing their reactivity and selectivity. This paper presents the preparation and characterization of an active metal nanoparticle-support polymer type composite membrane, based on osmium nanoparticles obtained in situ on a polypropylene hollow fiber membrane. Osmium nanoparticles are generated from a solution of osmium tetroxide in tert-butyl alcohol by reduction with molecular hydrogen in a contactor with a polypropylene membrane. The composite osmium-polypropylene hollow fiber obtained membranes (Os-PPM) were characterized from the morphological and structural points of view: scanning electron microscopy (SEM), high resolution SEM (HR-SEM), energy dispersive spectroscopy analysis (EDAX), X-ray diffraction analysis (XRD), Fourier transform Infrared (FTIR) spectroscopy, thermal gravimetric analysis, and differential scanning calorimetry (TGA, DSC). The process performance was tested in a redox process of $p$-nitrophenol and 10-undecylenic (10-undecenoic) acid, as a target substance of biological or biomedical interest, in solutions of lower aliphatic alcohols in a membrane contactor with a prepared composite membrane. The characteristics of osmium nanoparticles-polypropylene hollow fiber membranes open the way to biological and biotechnological applications. These membranes do not contaminate the working environment, operate at relatively low temperatures, provide a large contact area between reactants, allow successive oxidation and reduction operations in the same module, and help to recover the reaction mass by ultrafiltration. The results obtained show that the osmium-polypropylene composite membrane allows the reduction of $p$-nitrophenol or the oxidation of 10-undecylenic acid, the conversion depending on the concentration in the lower aliphatic alcohol, the nature of the lower aliphatic alcohol, and the oxidant or reducing flow through the membrane contactor.

Keywords: metal nanoparticles-polymer membranes; osmium nanoparticle; osmium nanoparticlespolymer membranes; polypropylene hollow fiber membranes; osmium nanoparticles-polypropylene hollow fiber membranes; redox processes; membrane reactor; reduction; oxidation; $p$-nitrophenol; 10-undecylenic acid 


\section{Introduction}

The development of membranes and membrane processes involving composite membranes has gained great importance with the progress made in obtaining nanoparticles with a well-controlled composition, shape, and size distribution [1,2]. Obviously, the nature of the nanoparticles used in obtaining membranes is of overwhelming importance for selectivity, reactivity, or effect on membrane processes (Figure 1). Thus, polymeric nanoparticles based on carbon, oxide, metals, or their compounds have been used for the preparation of composite membranes both in separation processes and in various reaction processes: esterification, etherification, reduction, and oxidation [2-4]. At the same time, intense studies have followed the influence of the size and shape of nanoparticles from a certain material on the performance of composite membranes [5,6]. The composite membranes made using metal nanoparticles (silver, gold, copper, nickel, or palladium) have a special place, which brought significant improvements in selectivity and reactivity [7-10].

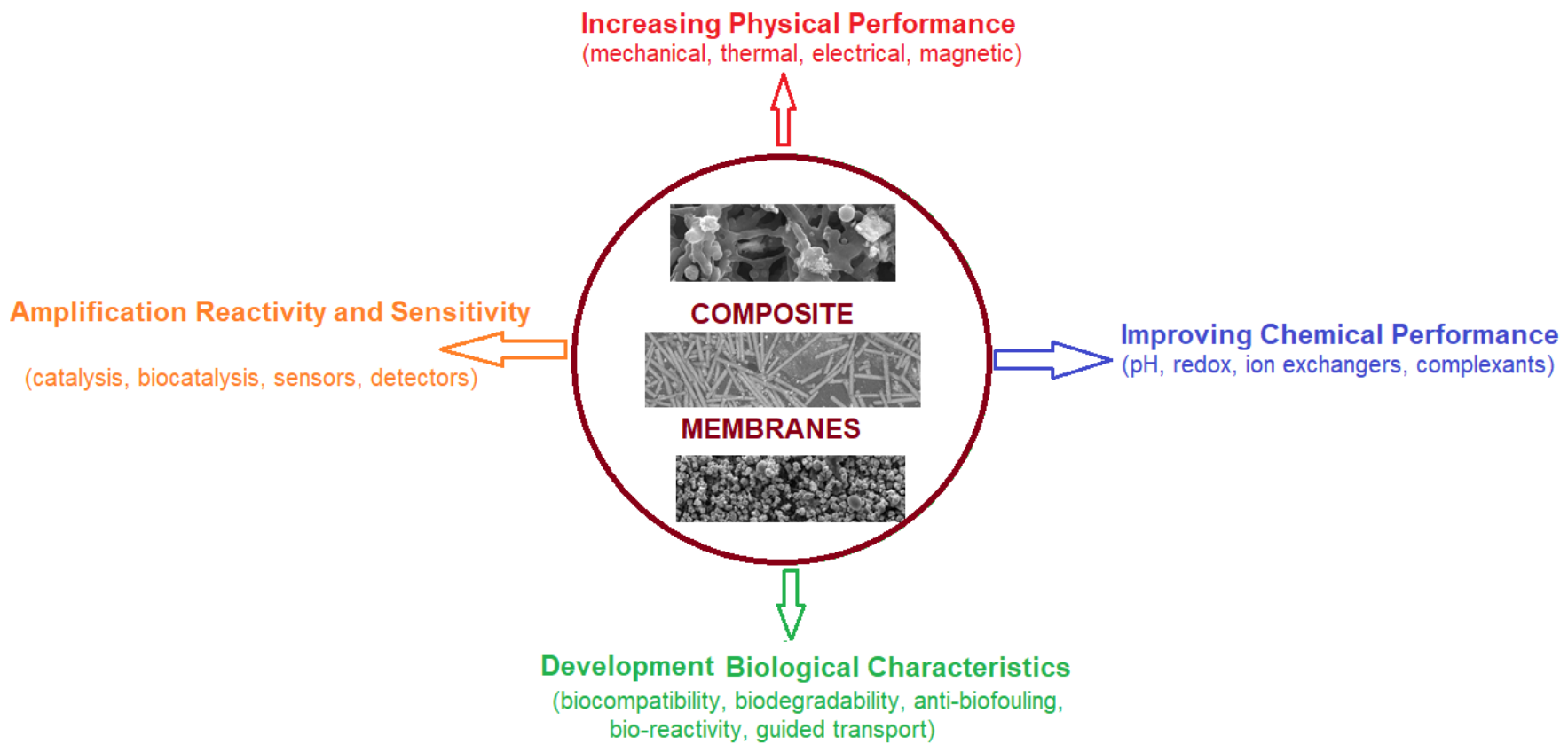

Figure 1. Composite membranes based on nanoparticles and the specific effects.

As outlined in Figure 1, the use of nanoparticles in the realization of composite membranes and the processes based on them has brought important benefits to users, such as:

- Increasing physical performance: mechanical, thermal, electrical, or magnetic [11-14],

- Improving chemical performance: $\mathrm{pH}$, redox, ion exchange, complexation [15-18],

- Amplification of activity and sensitivity: catalysis, bio-catalysis, sensors, detector [19-22], and

- Development of biological characteristics: biocompatibility, biodegradability, antibiofouling, guided transport [22-26].

Composite membranes based on metal nanoparticles fit in a very special way in all these directions of development of membrane processes. However, the reactivity or catalytic activity are among the best studied and used characteristics of metal nanoparticlepolymer based composite membranes [27-31]. Although they have special properties, osmium and its compounds have been used relatively little in membrane processes [32,33], the main application being the metallization of polymeric or biological membranes for studies in electron microscopy [34]. 
Due to its chemical inertia, even against aggressive environments [35], osmium can be an interesting membrane material for the construction of membrane reactors aimed at hydrogenation or oxidation $[30,36]$.

Making metal-polymer composite membranes is of interest from the perspective of increasing the physical-chemical and process performances, especially when it is represented by a chemical reaction. The use of osmium as a membrane material can be an economic disadvantage due to the high price, but when used as nanoparticles generated from an accessible material, such as osmium tetroxide, this aspect is overcome (Figures S1-S4).

At the same time, osmium obtained by reducing osmium tetroxide waste on a porous polymeric support can be a useful means of recovery, especially since in catalytic reactions, it is known for selectivity [37,38], regiospecificity [39,40], and stereospecificity [41].

The osmium-polymer (Os-P) membranes can be used in reduction or oxidation reactions, and as target substances can be considered those of interest for environmental, biological, or biomedical protection, such as p-nitrophenol [42-46] and 10-undecylenic acid [47-51].

The characteristics of osmium nanoparticles-polypropylene hollow fiber membranes open the path to biological and biotechnological applications. We can mention that these membranes:

- Do not contaminate the working environment,

- Operate at relatively low temperatures,

- Provide a large contact area between reactants,

- Help to recover the reaction mass by ultrafiltration, and

- Allow successive oxidation and reduction operations in the same module.

This paper presents the preparation and characterization of a composite membrane of active metal nanoparticle-support polymer type, based on osmium nanoparticles obtained in situ on a polypropylene hollow fiber membrane and its use in the transformation of 10-undecylenic acid or $p$-nitrophenol by oxidation and reduction.

\section{Experiments}

\subsection{Materials}

The reagents used in the presented work were of analytical grade and were used without other purification.

Methanol, ethanol, $i$-propanol and tert-butanol were purchased from Merck (Merck $\mathrm{KGaA}$, Darmstadt, Germany). Osmium tetroxide $\left(\mathrm{OsO}_{4}\right)$, $p$-nitrophenol, and 10-undecylenic (10-undecenoic) acid (>95\%) were purchased from Sigma-Aldrich (Merck KGaA, Darmstadt, Germany).

The purified water characterized by $18.2 \mu \mathrm{S} / \mathrm{cm}$ conductivity was obtained with a RO Millipore system (MilliQ®Direct 8 RO Water Purification System, Merck KGaA, Darmstadt, Germany).

The hollow polypropylene fibers used as membrane support (PPM) were provided by GOST Ltd., Perugia, Italy (Figure 2) [52,53].

Polypropylene hollow fiber membranes at a length of $700 \mathrm{~mm}$ and a diameter of $0.3 \mathrm{~mm}$ are assembled so as to achieve a filtering surface of $1 \mathrm{~m}^{2}[52,54]$. The fibers have a porosity of $40 \%[54,55]$ and a pore diameter of less than $0.2 \mu \mathrm{m}$ [56] (Figure 2). This type of module with polypropylene hollow fiber membranes allows operation over the entire $\mathrm{pH}$ range, in oxidizing or reducing solutions at temperatures up to $100{ }^{\circ} \mathrm{C}$ without dimensional changes and can be sterilized by known physical-chemical methods [57-59]. 


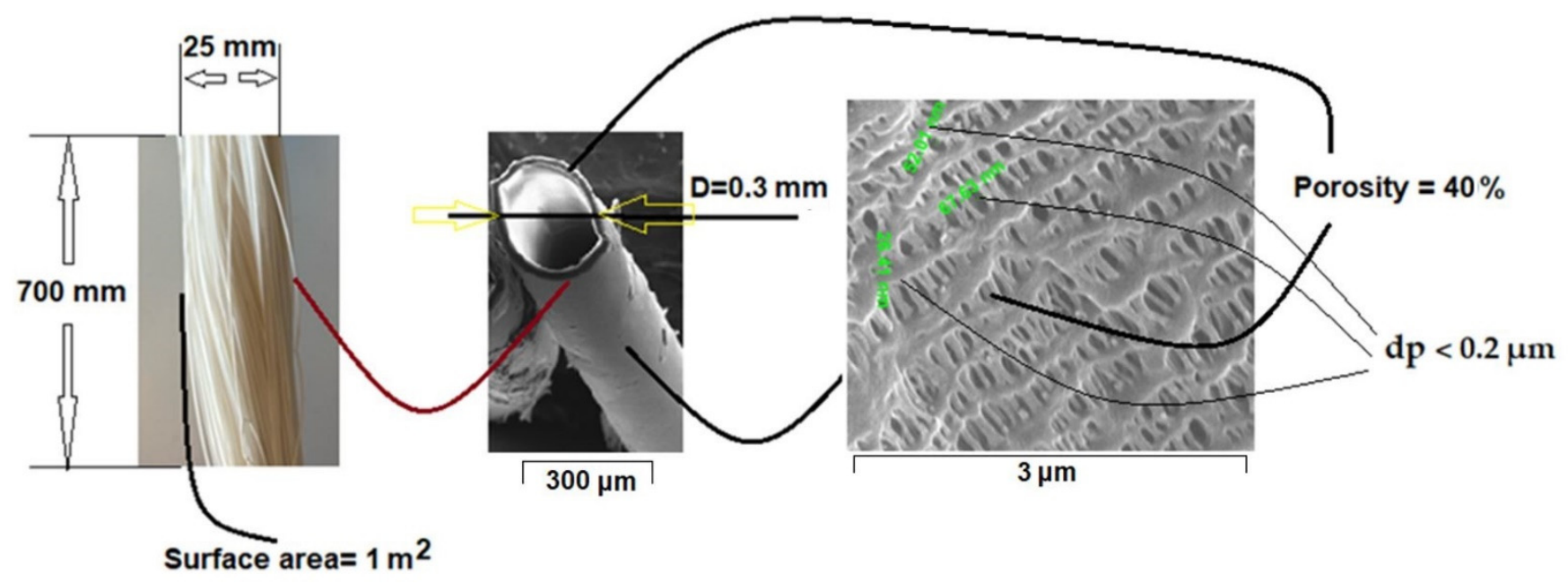

Figure 2. The typical characteristics of the polypropylene hollow fiber membrane (PPM).

\subsection{Procedures}

2.2.1. Preparation of Osmium Nanoparticles on Polypropylene Hollow Fiber Membranes

To make osmium nanoparticles-polypropylene hollow fibers composite membranes, on the support membrane is deposited metallic osmium from the reaction of osmium tetroxide dissolved in tert-butyl alcohol (1.5 and $2.0 \mathrm{~g} \mathrm{OsO}_{4}$ dissolved in $2500 \mathrm{~mL}$ tert-butyl alcohol), at a temperature of $25^{\circ} \mathrm{C}$ (Figure 3), when the chemical reaction takes place according to Equation (1).

$$
\mathrm{OsO}_{4}+4 \mathrm{H}_{2} \rightarrow \mathrm{Os}+4 \mathrm{H}_{2} \mathrm{O}
$$

The stages of reduction of osmium tetroxide on the polypropylene membrane are:

- Formation of the osmium tetroxide solution by dissolving $1 \mathrm{~g}$ of solid substance in $1000 \mathrm{~mL}$ of tert-butyl alcohol,

- Immersion of the fiber bundle in the alcoholic solution of osmium tetroxide,

- Reduction of osmium tetroxide with molecular hydrogen,

- Ethanol washing of osmium nanoparticles-polypropylene hollow fibers composite membranes, and

- $\quad$ Drying in a vacuum oven $\left(60^{\circ} \mathrm{C}\right)$.

The nanocomposite membrane samples containing osmium were characterized by scanning electron microscopy (SEM) and high resolution scanning electron microscopy (HR-SEM), energy dispersive spectroscopy analysis (EDAX), X-ray diffraction analysis (XRD), atomic absorption spectroscopy, and thermal analysis (TG, DSC).

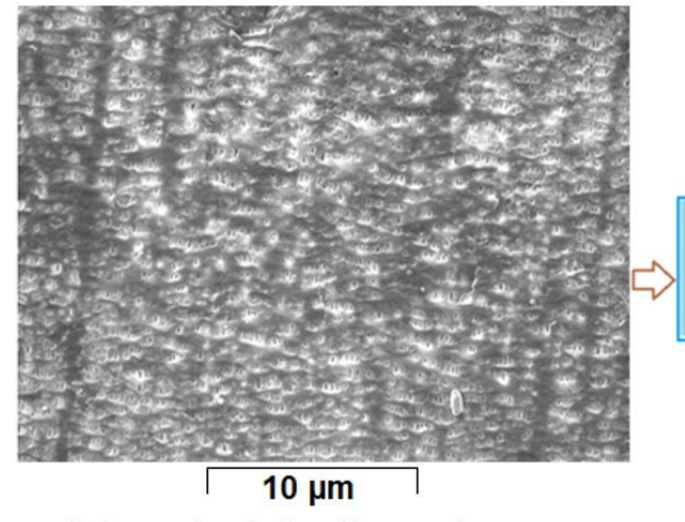

Polypropylene hollow fiber membrane

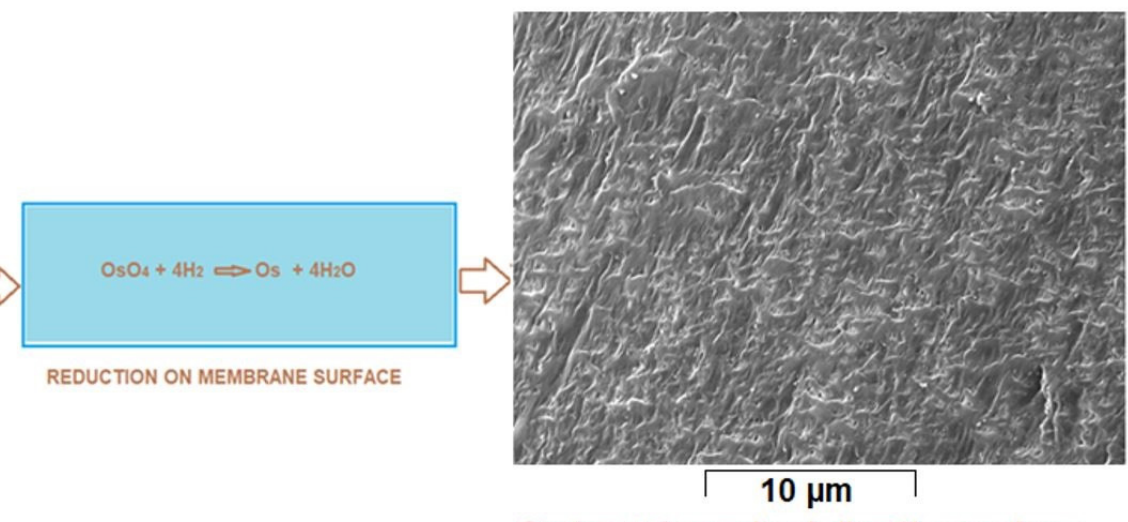

Osmium-polypropylene hollow fiber membrane

Figure 3. Obtaining osmium nanoparticles on polypropylene hollow fiber membrane. 
For X-ray diffraction analysis (XRD), atomic absorption spectroscopy, and thermal analysis (TG, DSC) the samples were ground at a colloidal ball mill (Retsch PM 100, VIOLA-Shimadzu, Bucharest, Romania) provided with ceramic grinding bodies.

\subsubsection{Carrying out the Process of Oxidation or Reduction}

The impregnated membrane bundle was mounted in a reaction module similar to that extensively described in our previous works [60-62]. A bundle of composite fibers was inserted into this housing and subsequently immobilized with acrylic polymer, thus obtaining a membrane contactor similar to a tubular heat exchanger. This module was placed in the working installation (Figure 4a). The circulation of fluids through a membrane is shown in Figure $4 b$.

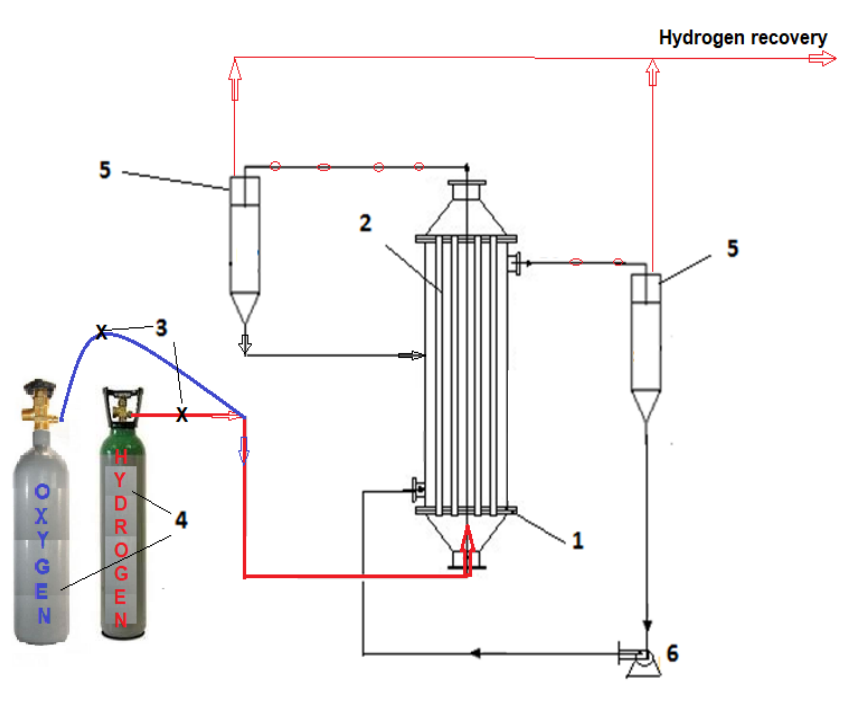

(a)

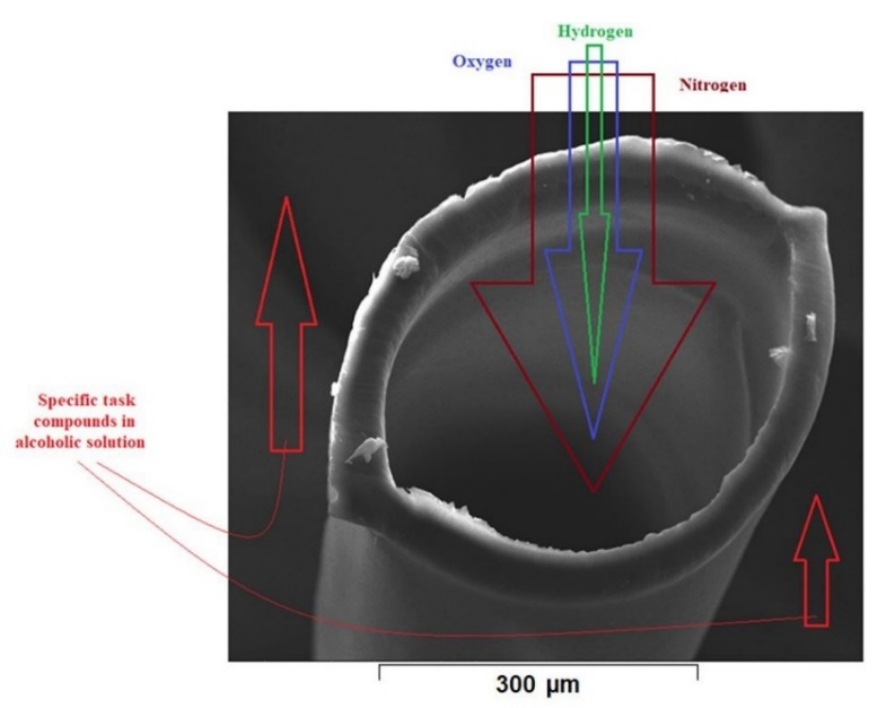

(b)

Figure 4. (a) The schematic presentation of the 10-undecylenic acid oxidation or $p$-nitrophenol reduction installation: 1: membrane contactor; 2: polypropylene hollow fiber membranes; 3, 4: hydrogen or oxygen source; 5: gas-liquid separator; 6 : pump for solution in tert-butyl alcohol (methanol, ethanol, or propanol); and (b) fluid circulation through the system.

The solution of $p$-nitrophenol or 10-undecylenic acid in tert-butyl alcohol (ethanol or propanol) was conveyed through the membranes, and hydrogen or molecular oxygen was transported at normal pressure $(1 \mathrm{~atm})$ through the composite membranes.

Three samples of $1 \mathrm{~mL}$ from the alcoholic $p$-nitrophenol or 10-undecylenic acid synthesized solutions were periodically spectrophotometrically analyzed [62,63].

The conversion ( $\eta \%$ ) of analytes calculated using the solution's concentration (2) or absorbance (3) $[64,65]$ were:

$$
\eta(\%)=\frac{\left(c_{0}-c_{f}\right)}{c_{0}} \times 100
$$

where $c_{f}$ is the final concentration of the solute (10-undecylenic acid or $p$-nitrophenol) and $c_{\mathrm{o}}$ is the initial concentration of solute (10-undecylenic acid or $p$-nitrophenol).

$$
\eta(\%)=\frac{\left(A_{0}-A_{s}\right)}{A_{0}} \times 100
$$

$A_{0}$ is the initial sample solution absorbance and $A_{s}$ is the current sample absorbance.

If the reduction of $p$-nitrophenol leads to $p$-aminophenol, the oxidation of 10-undecylenic acid leads to a variety of reaction products. That is why in this study, only the conversion was followed. However, to illustrate the complexity of the reaction mass, $10 \mathrm{~mL}$ of solutes was subjected to chromatography on a $60 \mu \mathrm{m}$ silica column and the separated compounds were identified through Fourier transform infrared (FTIR) spectrometry (see Table S1). 
After the processing, nitrogen was introduced into the module for two hours to remove hydrogen or oxygen. In the specific case of oxidation, after the process, nitrogen was introduced into the module for two hours to remove oxygen, then hydrogen for two hours to reduce any traces of osmium oxide, and, finally, nitrogen was introduced again for two hours. The module was opened for membrane sampling for analysis after the reaction mass was aspirated, through membranes (a vacuum nanofiltration was performed at $100 \mathrm{~mm} \mathrm{H}_{2} \mathrm{O}$ to maximize the reaction mass (permeate) and the retention of nanoparticles and nanoparticle aggregates of osmium (concentrate)).

Successive nitrogen washing and hydrogen gas reduction operations ensured an osmium-free reaction mass and recovery of any osmium loss. The operations described are also mandatory to ensure the safety at work of the laboratory and the staff.

\subsection{Equipment}

The microscopy studies, SEM and HR-SEM, were performed on a Hitachi S4500 system (Hitachi High—Technologies Europe GmbH, Mannheim, Germany).

X-ray diffraction analyses (XRD) were recorded using PANalytical X'Pert Pro MPD equipment (PANalytical B.V., Almelo, The Netherlands) with a CuK $\alpha$ Cradiation source, and $2 \theta$ measurement range, from 10 to $90^{\circ} \mathrm{C}$.

Thermal analysis (TG, DSC) was performed with a STA 449C Jupiter apparatus, from Netzsch (NETZSCH-Gerätebau GmbH, Selb, Germany). Each sample weighed approximately $10 \mathrm{mg}$. The samples were placed in an open alumina crucible and heated up to $900{ }^{\circ} \mathrm{C}$ with $10 \mathrm{~K} \cdot \mathrm{min}^{-1}$ rate, under flow of $50 \mathrm{~mL} \cdot \mathrm{min}^{-1}$ dried air. As reference, we used an empty alumina crucible. The evolved gases were analyzed with a FTIR Tensor 27 from Bruker (Bruker Co., Ettlingen, Germany), equipped with a thermostat gas cell.

The UV-Vis analyses of the 10-undecylenic acid solutions were done on a Spectrophotometer CamSpec M550 (Spectronic CamSpec Ltd., Leeds, UK).

The electrochemical processes were followed up with a PARSTAT 2273 Potentiostat (Princeton Applied Research, AMETEK Inc., Berwyn, PA, USA). It has been used a glass cell with three electrodes setup.

Cyclic voltammetry was performed for a potential sweep between $-0.5 \mathrm{~V}$ and $+1.23 \mathrm{~V}$, at a scan rate of $50 \mathrm{mV} / \mathrm{s}$. The experimental procedure took place at room temperature.

The UV-Vis studies on the nanoparticles samples composition were performed on dual-beam UV equipment-Varian Cary 50 (Agilent Technologies Inc., Santa Clara, CA, USA) - at a resolution of $1 \mathrm{~nm}$, spectral bandwidth $1.5 \mathrm{~nm}$, and $300 \mathrm{~nm} / \mathrm{s}$ scan rate. The samples' UV-Vis spectra were recorded for a wavelength from $200 \mathrm{~nm}$ to $800 \mathrm{~nm}$, at room temperature, using $10 \mathrm{~mm}$ quartz cells.

The $\mathrm{pH}$ of the medium was followed up with a combined selective electrode (HI 4107, Hanna Instruments Ltd, Leighton Buzzard, UK) and a multi-parameter system (HI 5522, Hanna Instruments Ltd., Leighton Buzzard, UK).

To assess and validate the content in metal ions, the atomic absorption spectrometer AAnalyst 400 AA Spectrometer (Perkin Elmer Inc., Shelton, CT, USA) with a single-element hollow-cathode lamp was used, driven by WinLab32-AA software (Perkin Elmer Inc., Shelton, CT, USA).

\section{Results and Discussions}

The present study used osmium nanoparticles-polypropylene hollow fiber membranes selected from previous experiments on osmium nanoparticles-polymer membranes [63], which included three polymers of different hydrophobicity: polyethylene, polysulfone, and cellulose acetate.

The choice of polypropylene hollow fiber membrane was determined both by the nature of the environment that the studies in this paper address (alcoholic solutions) and by the need for a large contact area. 
Polypropylene hollow fiber membrane has the advantage of a chemical resistance over the entire $\mathrm{pH}$ range, but also in oxidizing, reducing, or temperature environments up to $90-100{ }^{\circ} \mathrm{C}$.

This paper presents the recovery of osmium tetroxide, left from various stages of processing in electron microscopy, as follows:

- The preparation of composite membranes based on osmium-polypropylene hollow fiber (Os-PP), by in situ reduction of the osmium tetroxide from tert-butyl alcohol solution with molecular hydrogen,

- Morpho-structural characterization of the obtained osmium-polypropylene hollow fiber composite membranes,

- The reduction of $p$-nitrophenol with molecular hydrogen in a module using osmiumpolypropylene hollow fiber composite membranes, and

- Oxidation of 10-undecylenic acid with osmium-polypropylene hollow fiber composite membranes using molecular oxygen.

3.1. The Preparation and Characterization of the Composite Membrane Osmium-Polypropylene Hollow Fiber (Os-PP) by In Situ Reduction of Osmium Tetroxide

Obtaining a composite membrane intended for a membrane reactor must combine the special physical-chemical resistance of the support with the selectivity and versatility of metallic nanoparticles.

The membrane support chosen for the osmium nanoparticles-polymer composite membrane is the polypropylene hollow fiber membrane that ensures the possibility of working in aqueous or non-aqueous environments, over the entire $\mathrm{pH}$ range, at temperatures up to $90-100^{\circ} \mathrm{C}$ and multiple washing or sterilization variants (hypochlorite, hydrogen peroxide, alkaline, or basic solutions).

In this study, the most important characteristics were the porosity (minimum 40\%), pore diameter (less than $0.2 \mu \mathrm{m}$ ), and small thickness of approx. $20 \mu \mathrm{m}$ (Figures 5 and S4). These characteristics allowed the intimate contact of hydrogen, through the membrane contactor which was also the membrane preparation installation (Figure 4), with the solution of osmium tetroxides in tert-butyl alcohol, in order to reduce the metallic osmium that thus develops in the pores (Figures 6 and 7). Molecular hydrogen was conveyed through the polypropylene hollow fibers membranes at a flow rate of $1 \mathrm{~L} / \mathrm{min}$, and the solution of osmium tetroxide in tert-butyl was maintained outside the fibers.

The concentration of the solution of osmium tetroxide in tert-butyl alcohol was chosen at $0.6 \mathrm{~g} / \mathrm{L}$ for the Os-PP1 membrane and $0.8 \mathrm{~g} / \mathrm{L}$ for the Os-PP2 membrane. The concentrations of the solutions were chosen in order to be able to compare these composite membranes with the previously obtained and reported membrane, Os-PP0 [64]. The concentration of the solution of osmium tetroxide in tert-butyl alcohol was $0.4 \mathrm{~g} / \mathrm{L}$. The increase in concentration of osmium tetroxide had in view obtaining a high concentration of osmium atoms at the surface of the raw membranes (Figure 7) highlighted by energy dispersive spectroscopy analysis (EDAX) (Table 1).

Table 1. Energy dispersive spectroscopy analysis (EDAX) for the osmium-polymer membranes.

\begin{tabular}{|c|c|c|c|c|c|c|c|c|c|}
\hline \multirow{2}{*}{$\begin{array}{c}\begin{array}{c}\text { Composite } \\
\text { Membranes }\end{array} \\
\begin{array}{c}\text { Surface } \\
\text { Composition }\end{array}\end{array}$} & \multicolumn{3}{|c|}{ (Os-PP0) } & \multicolumn{3}{|c|}{ (Os-PP1) } & \multicolumn{3}{|c|}{ (Os-PP2) } \\
\hline & $\begin{array}{c}\text { Weight } \\
(\%)\end{array}$ & $\begin{array}{c}\text { Atomic } \\
(\%)\end{array}$ & $\begin{array}{c}\text { Error } \\
(\%)\end{array}$ & $\begin{array}{c}\text { Weight } \\
\text { (\%) }\end{array}$ & $\begin{array}{c}\text { Atomic } \\
(\%)\end{array}$ & $\begin{array}{c}\text { Error } \\
(\%)\end{array}$ & $\begin{array}{c}\text { Weight } \\
(\%)\end{array}$ & $\begin{array}{c}\text { Atomic } \\
(\%)\end{array}$ & $\begin{array}{c}\text { Error } \\
(\%)\end{array}$ \\
\hline CK & 49.36 & 90.32 & 9.44 & 43.22 & 88.09 & 9.81 & 39.90 & 85.94 & 9.98 \\
\hline $\mathrm{OK}$ & 2.89 & 4.05 & 29.4 & 3.29 & 5.03 & 31.05 & 3.98 & 6.43 & 33.41 \\
\hline Os L & 47.75 & 5.63 & 11.12 & 53.49 & 6.88 & 13.32 & 56.12 & 7.63 & 14.03 \\
\hline
\end{tabular}




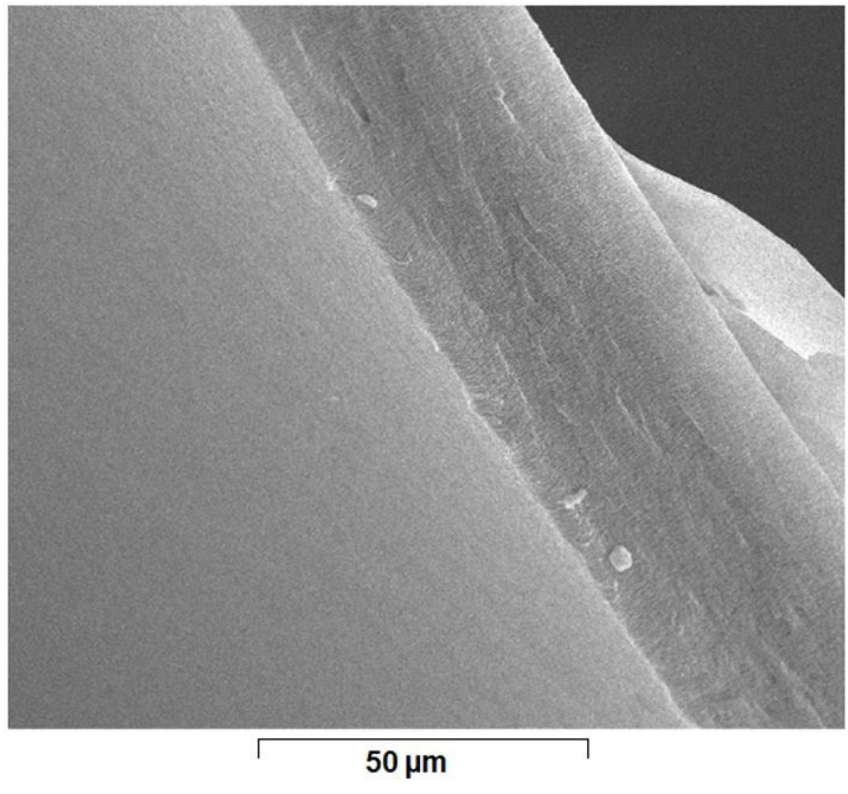

(a)

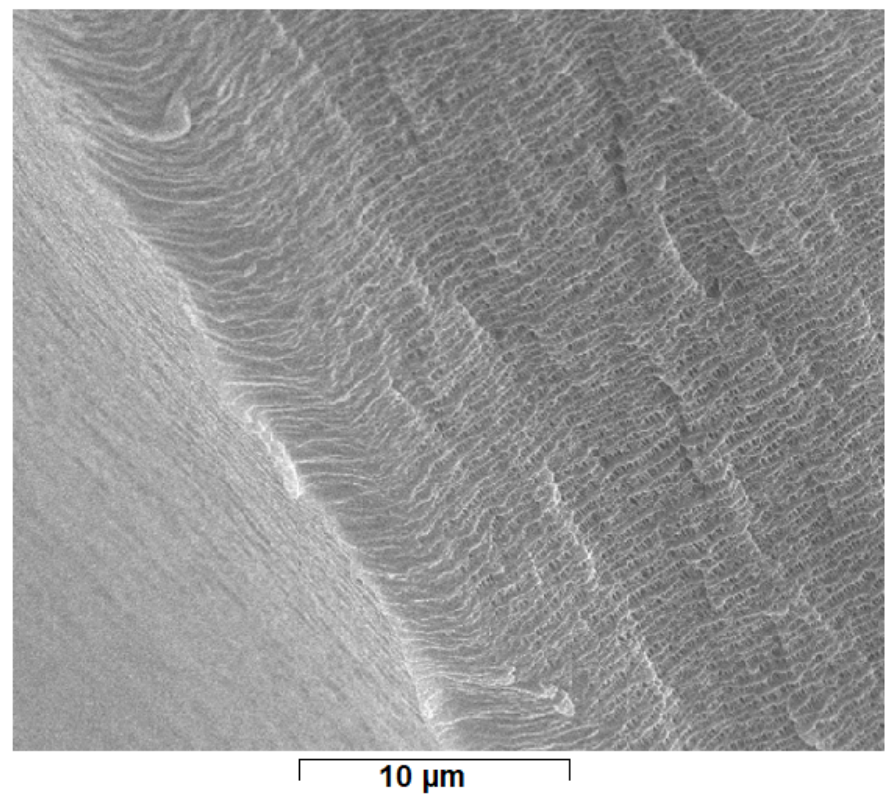

(b)



(c)

Figure 5. Scanning electron microscopy (SEM) of the uniformity of porosity and dimensional distribution of polypropylene hollow fibers membranes pores at various magnitudes: $(\mathbf{a}) \times 2000 ;(\mathbf{b}) \times 8000$; and $(\mathbf{c}) \times 20,000$.

Although the local analyses (on the surface) showed the presence of osmium nanoparticles and nanoparticles aggregates, the X-ray diffraction analysis (XRD) being a global method (a quantity of Os-PP membranes ground at the mill was analyzed) was more difficult to interpret, but the lines specific to metallic osmium were still highlighted (see Figure S5 in the Supplementary Material).

To overcome this aspect, extensive energy dispersive spectroscopy analysis (EDAX) analyses were performed. The EDAX diagrams, having a formal aspect presented in Figures $8 \mathrm{a}$ and S6, showed the presence of carbon and osmium on the surface, but also of oxygen, which comes both from the conditioning agent of polypropylene hollow fibers membranes and from the working solvent, or the hydrating water that appears in the reduction of osmium tetroxide (see also Equation (1)). 




\section{OsO4 solution Hydrogen in t-butyl alcohol}

Figure 6. Schematic presentation of the contactor for reducing osmium tetroxide dissolved in tertbutyl alcohol at aggregates of metallic osmium nanoparticle with molecular hydrogen.

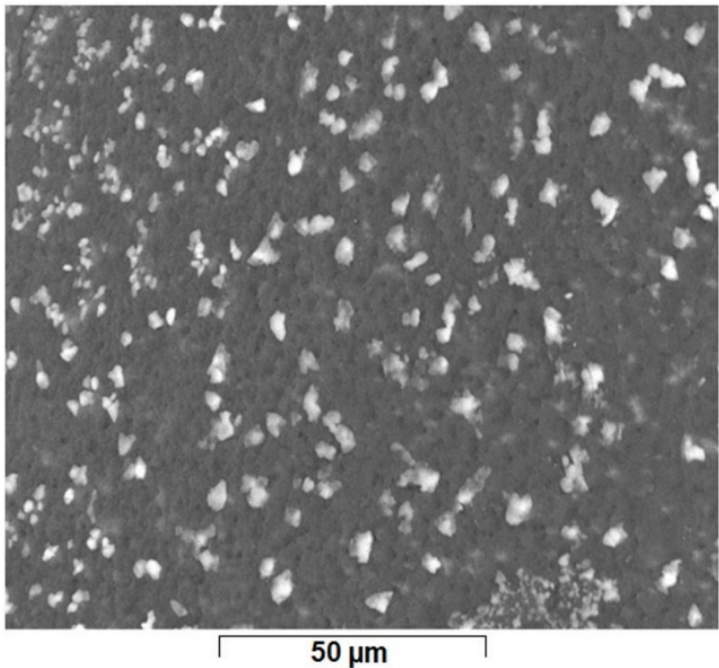

(a)

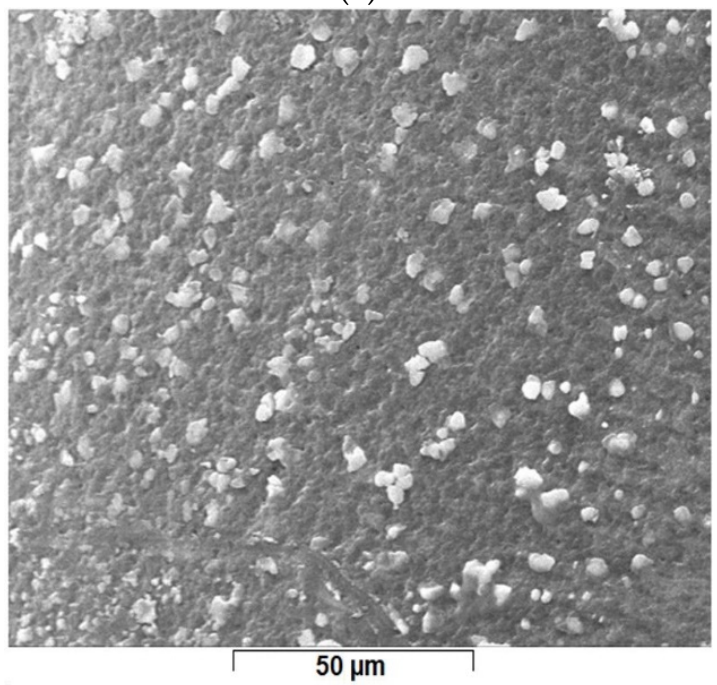

(c)

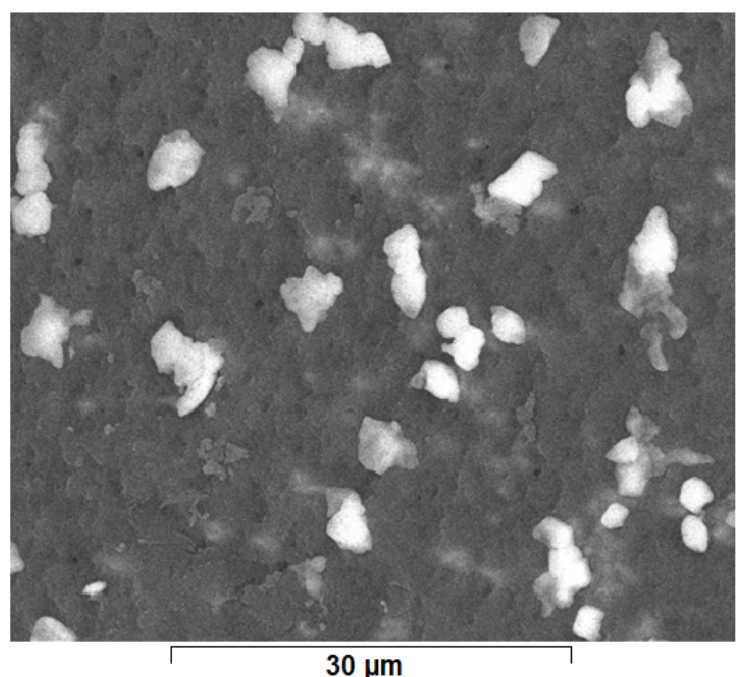

(b)

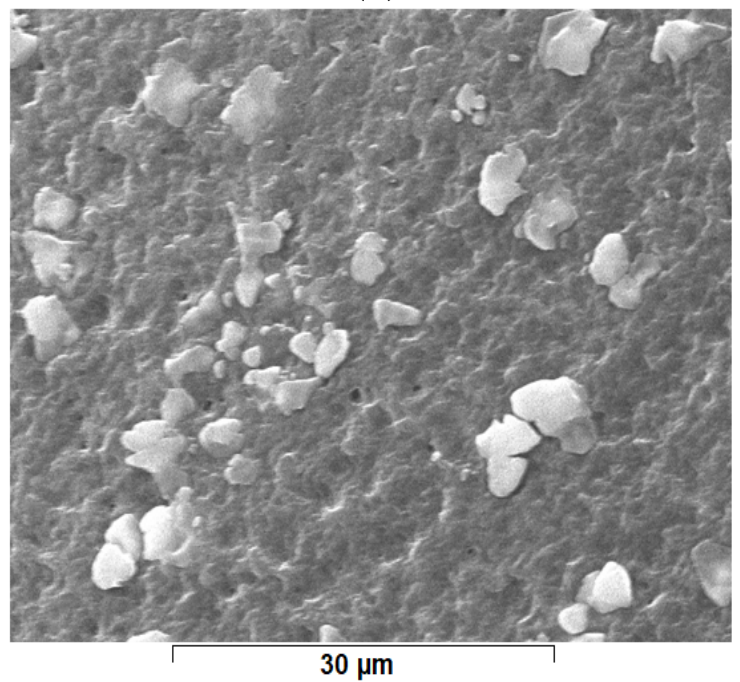

(d)

Figure 7. The scanning electron microscopy of the membrane support in the pores of which nanoparticle aggregates of metallic osmium have developed: raw osmium nanoparticles-polypropylene hollow fibers composite membrane 1 (Os-PP1) (a) $\times 2000$ and (b) $\times 5000$; and raw osmium nanoparticles-polypropylene hollow fibers composite membrane 2 (Os-PP2) (c) $\times 2000$ and $(\mathbf{d}) \times 5000$. 




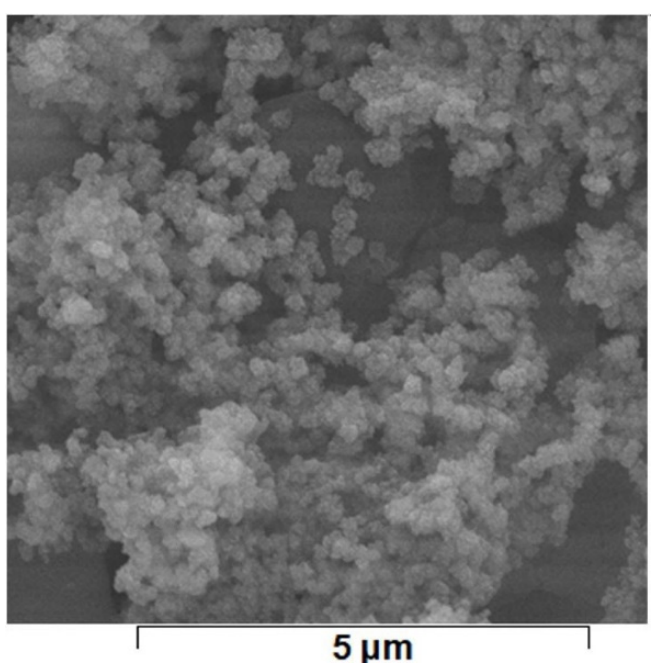

(b)

(a)

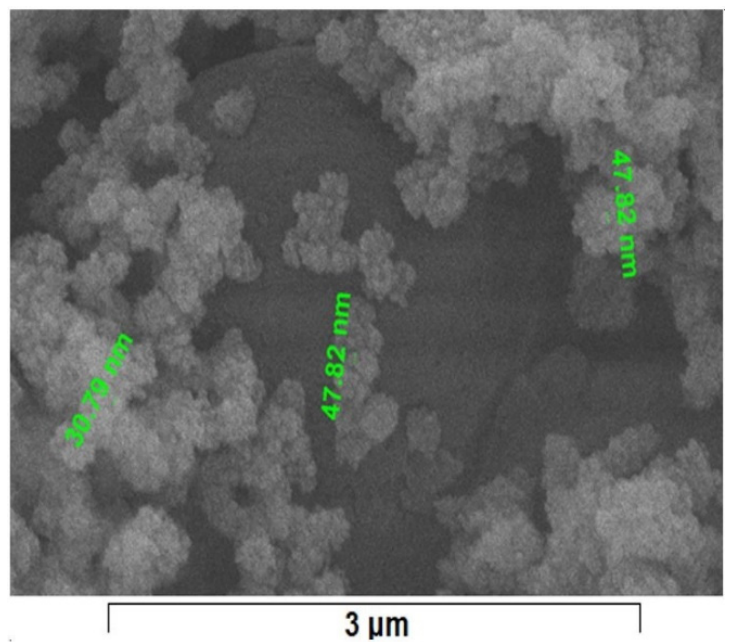

(c)

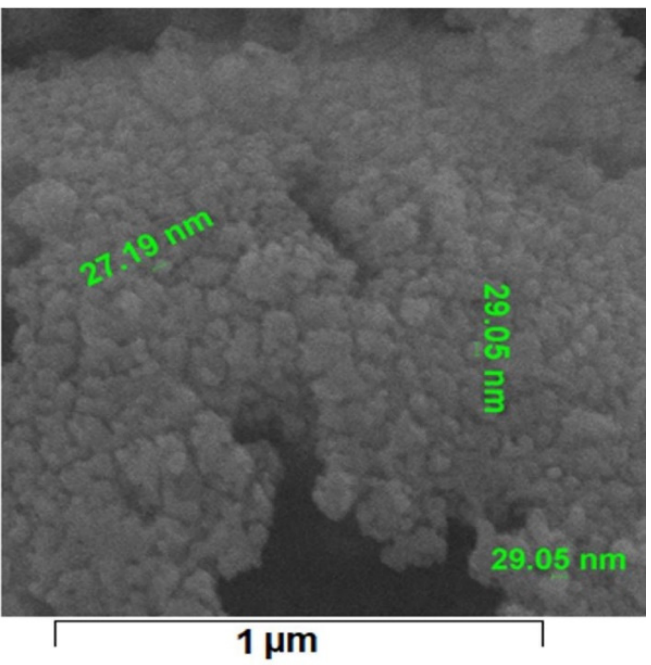

(d)

Figure 8. Formal energy dispersive spectroscopy analysis (EDAX) for the raw osmium nanoparticles-polypropylene hollow fibers composite membrane (Os-PP) (a), and high-resolution scanning electron microscopy (HR-SEM) of the specific osmium nanoparticles distribution on raw membrane surface: $\times 20,000(\mathbf{b}) ; \times 50,000(\mathbf{c})$; and $\times 100,000$ (d). 
The dimensions of osmium nanoparticles (Figure $8 b-d$ ) were tracked by detailing the nanoparticle aggregates on the raw osmium nanoparticles-polypropylene hollow fibers composite membranes.

By scanning electron microscopy analysis (SEM) coupled with energy dispersive spectroscopy analysis (EDAX), it was possible to follow the distributions of osmium nanoparticles on the membranes recovered after the microfiltration of the respective reaction system: tert-butanol (Figure 9a); mass of reagents after the reduction process (Figure 9b); and mass of reagents after the oxidation process (Figure 9c).

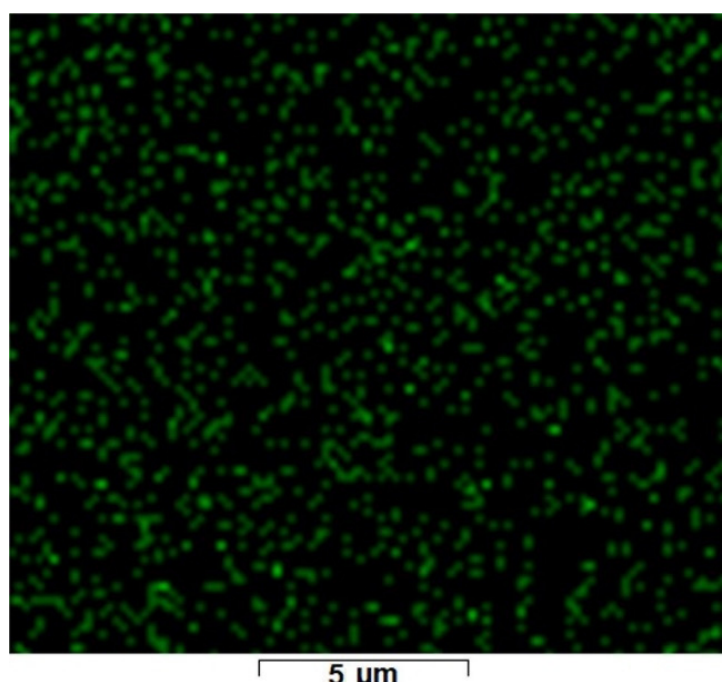

(a)

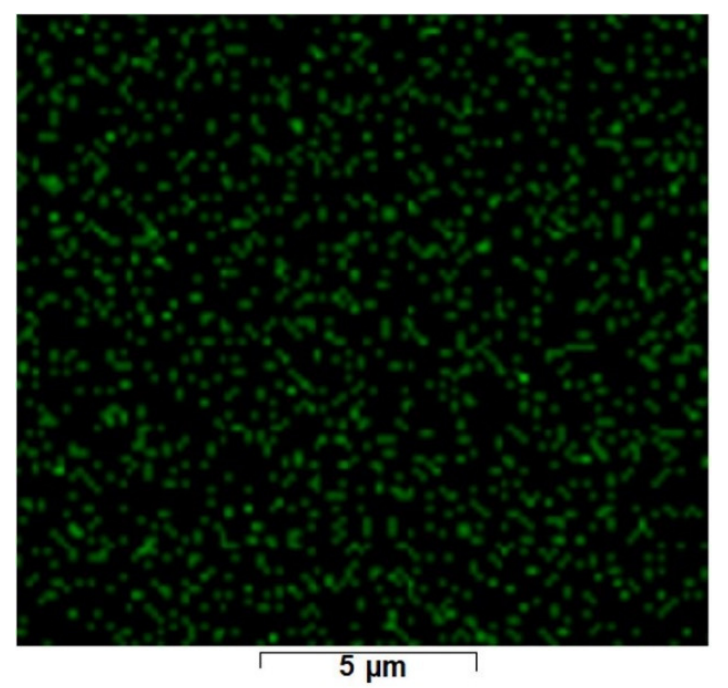

(b)

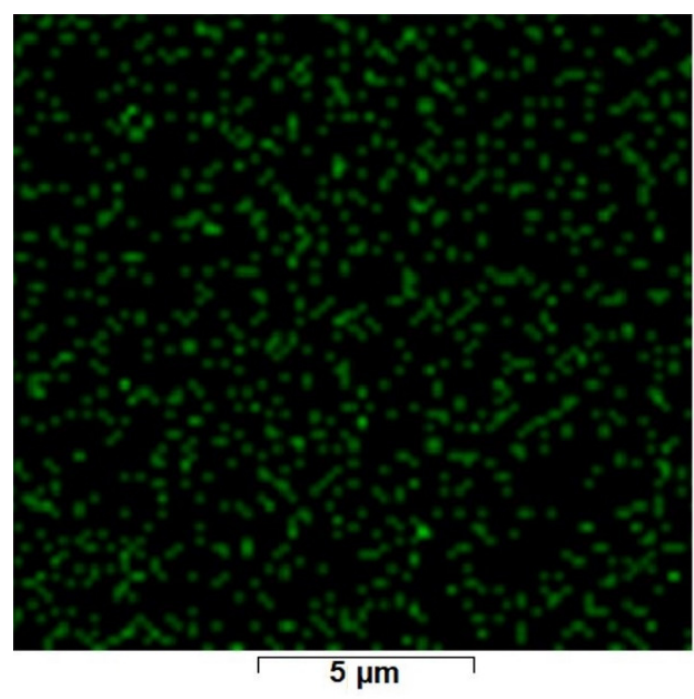

(c)

Figure 9. The energy dispersive spectroscopy analysis (EDAX) for the osmium nanoparticles-polypropylene hollow fibers composite membrane before (a); and after reduction (b); or oxidation (c) processes.

The distribution of osmium on the surface of the target membrane was performed both before and after the redox processes (Figure 9a-c; see also Figure S6). The relatively uniform distribution on the membrane surface and the size of the nanoparticles were both remarkable. This uniform distribution of osmium nanoparticles on the processed membranes was due to the microfiltration process which, in addition to the disintegration effect, directed the nanoparticles on the surface and towards the interior of the pores, so that the map of nanoparticles reflected the pore distribution of the support membrane. The surface of $1 \mathrm{~m}^{2}$ represents a disadvantage for the study of nanoparticles, regardless of the analysis technique, due to dispersion (approx. 1.0-1.6 g/ $\mathrm{m}^{2}$ ). 
The thermal analysis of the composite membranes gives information on the component's interactions and membranes behavior at different temperatures. This is necessary in order to follow the performances in case of use at higher temperatures than the ambient one, and to fully characterize the composite material (Figure 10 and Table 2).

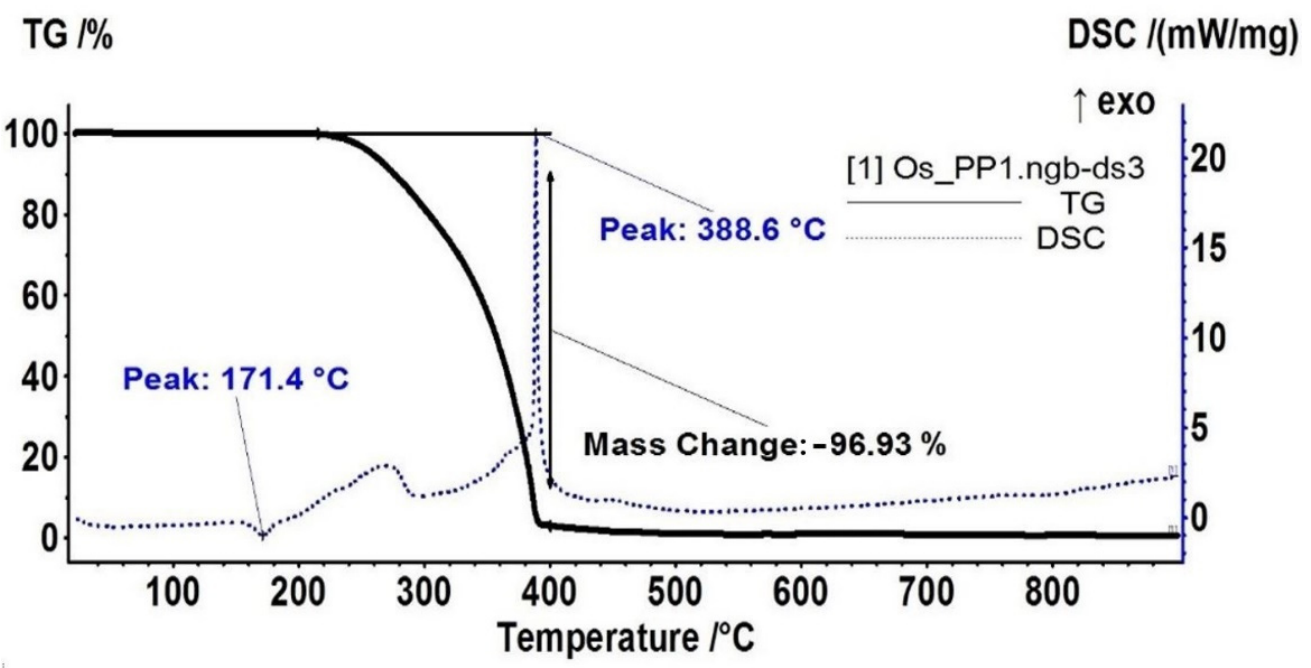

(a)

TG $1 \%$

$\mathrm{DSC} /(\mathrm{mW} / \mathrm{mg})$

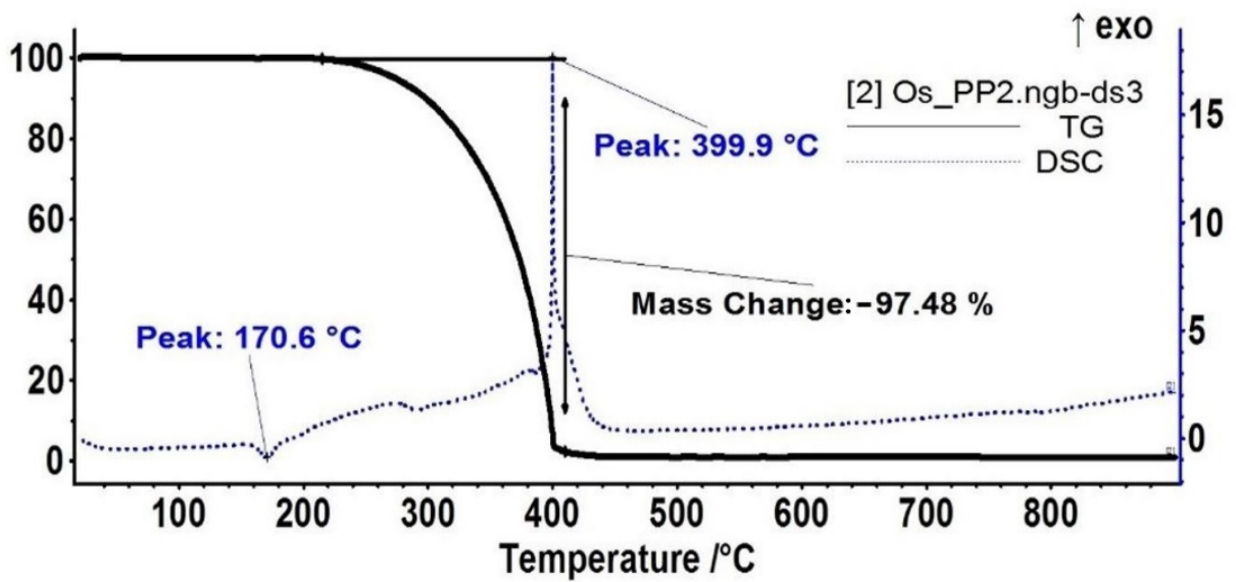

(b)

TG $/ \%$

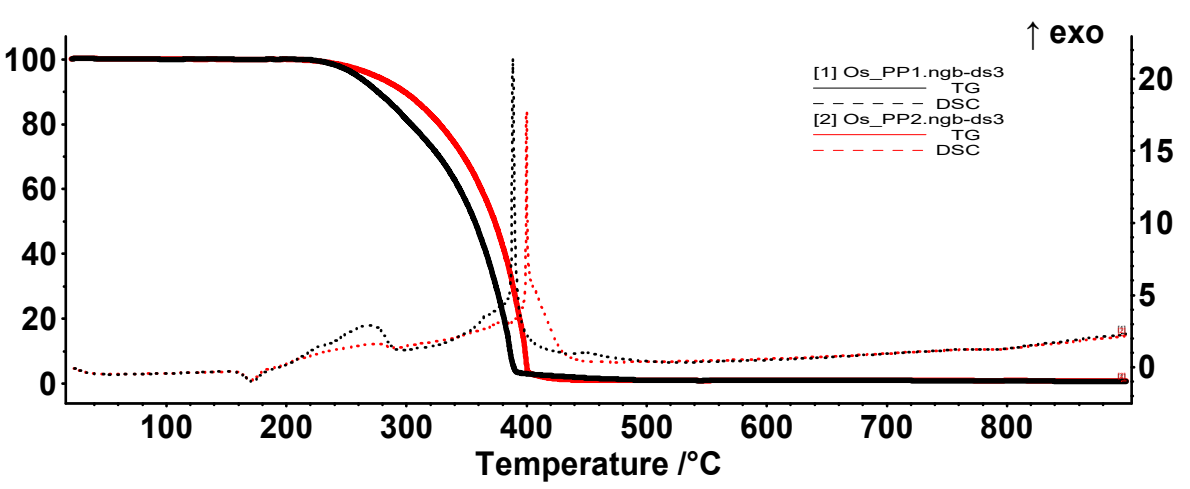

(c)

Figure 10. TG-DSC curves for osmium nanoparticles-polypropylene hollow fibers composite membranes: Os-PP1 (a); Os-PP2 (b); and their overlap (c). 
Table 2. Thermal characteristics of the obtained composite membranes.

\begin{tabular}{|c|c|c|c|c|c|c|c|}
\hline \multirow{2}{*}{ Sample } & $\mathbf{T}_{10}$ & $\mathbf{T}_{20}$ & $\mathbf{T}_{30}$ & $\mathbf{T}_{40}$ & $T_{50}$ & Melting Onset & Exo Burning \\
\hline & $\left({ }^{\circ} \mathrm{C}\right)$ & $\left({ }^{\circ} \mathrm{C}\right)$ & $\left({ }^{\circ} \mathrm{C}\right)$ & $\left({ }^{\circ} \mathrm{C}\right)$ & $\left({ }^{\circ} \mathrm{C}\right)$ & $\left({ }^{\circ} \mathrm{C}\right)$ & $\left({ }^{\circ} \mathrm{C}\right)$ \\
\hline Os-PP1 & 276.1 & 303.8 & 327.2 & 344.2 & 356.8 & 159.7 & 388.6 \\
\hline Os-PP2 & 298.3 & 327.6 & 347.7 & 362.3 & 373.5 & 160.4 & 399.9 \\
\hline
\end{tabular}

Both samples presented a similar degradation pathway but with some differences. The sample Os-PP2 had a higher thermal stability, the temperatures $\mathrm{T}_{10}-\mathrm{T}_{50}$ (at which $10-50 \%$ mass loss is recorded) being with $\sim 20^{\circ} \mathrm{C}$ higher.

The samples were stable up to $215^{\circ} \mathrm{C}$, with negligible or no mass loss recorded. On the DSC curve, the small endothermic peaks with onset at $159.7^{\circ} \mathrm{C}$ and $160.4{ }^{\circ} \mathrm{C}$, respectively, indicate the melting temperature. The higher value for the Os-PP2 sample indicates that the osmium compound was shielding the PP in a quantifiable measure.

After $215{ }^{\circ} \mathrm{C}$, the complex degradative-oxidative process for the polymeric part took place. The samples were partially oxidized but also some decomposition took place, the evolved gases being composed of $\mathrm{CO}_{2}$ and $\mathrm{H}_{2} \mathrm{O}$, but also saturated hydrocarbons and traces of $\mathrm{CO}$ and unsaturated hydrocarbons could be identified. $\mathrm{Up}$ to $300^{\circ} \mathrm{C}$, the decomposition and oxidation reactions were fairly equal, but after $300^{\circ} \mathrm{C}$, the oxidation reactions became predominant, with the burning taking place around $400^{\circ} \mathrm{C}$. The strong exothermic peak on DSC curve had maxima at $388.6{ }^{\circ} \mathrm{C}$ and $399.9^{\circ} \mathrm{C}$ for Os-PP1 and Os-PP2, respectively.

In order to obtain more information on the thermal processes, the gases evolved from thermal analysis were investigated by FTIR during heating in the $20-900{ }^{\circ} \mathrm{C}$ range. Figure 11 present the 3D FTIR data for the evolved gases.

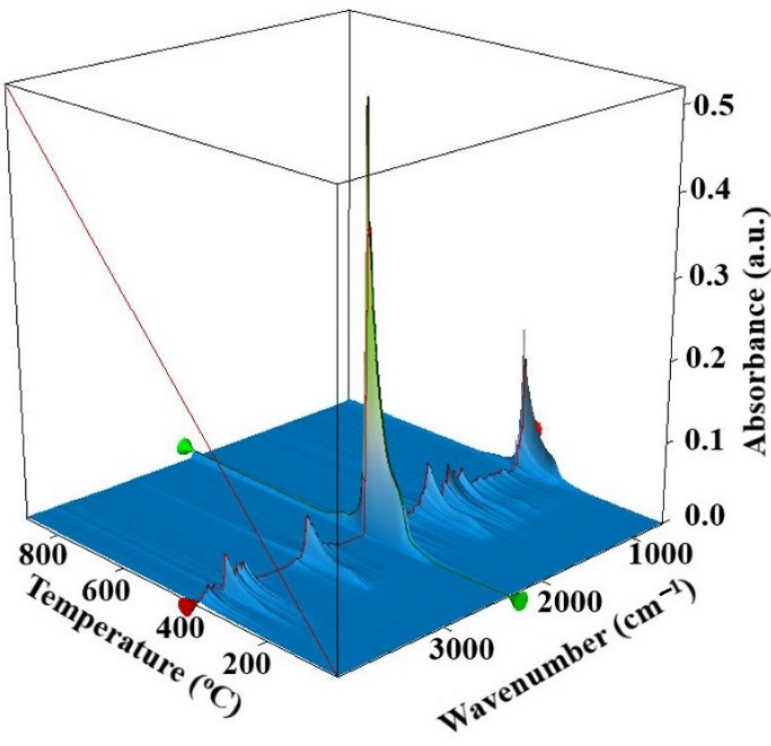

(a)

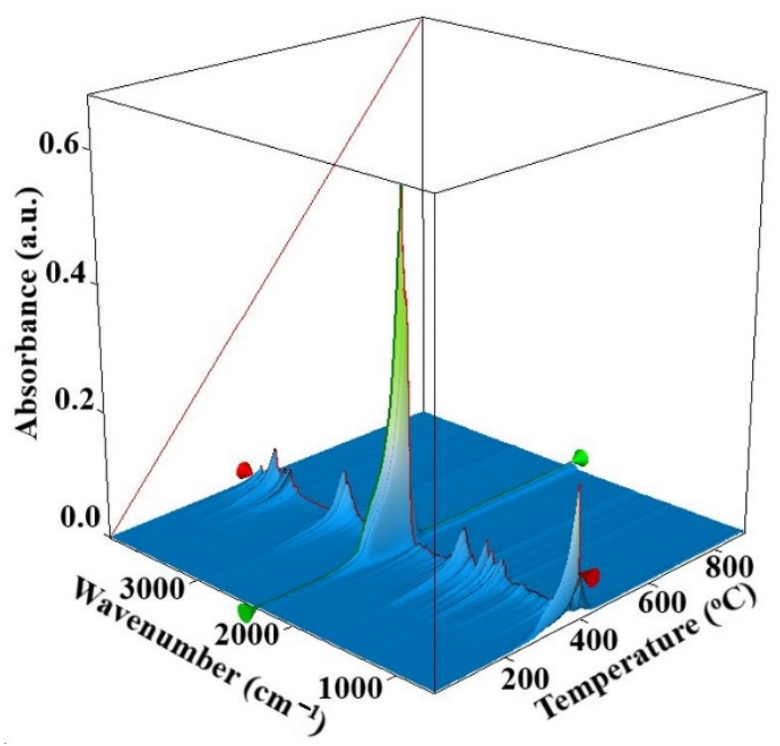

(b)

Figure 11. FTIR 3D chromatograms for evolved gases obtained for osmium nanoparticles-polypropylene hollow fiber composite membranes: Os-PP1 (a); and Os-PP2 (b).

The 3D FTIR chromatograms for Os-PP1 (Figure 11a) and Os-PP2 (Figure 11b) allow the extraction of individual FTIR spectrum of the exhaust gases at temperatures of interest. In this case, the beginning of the thermal decomposition was taken into account, at $270{ }^{\circ} \mathrm{C}$, in order to have related compositional information.

In the FTIR spectra for Os-PP1 at $270{ }^{\circ} \mathrm{C}$, and Os-PP2 at $274{ }^{\circ} \mathrm{C}$ (Figure 12), the presence of $\mathrm{CO}_{2}$ is mostly seen at $2355 \mathrm{~cm}^{-1}$, traces of $\mathrm{CO}$ at $2169 \mathrm{~cm}^{-1}$, water, but also the 
corresponding vibration of $\mathrm{Csp}^{3}-\mathrm{H}$ at $2964 \mathrm{~cm}^{-1}$. A small peak is observed at $3072 \mathrm{~cm}^{-1}$ (corresponding to $\mathrm{Csp}^{2}-\mathrm{H}$ fragments).

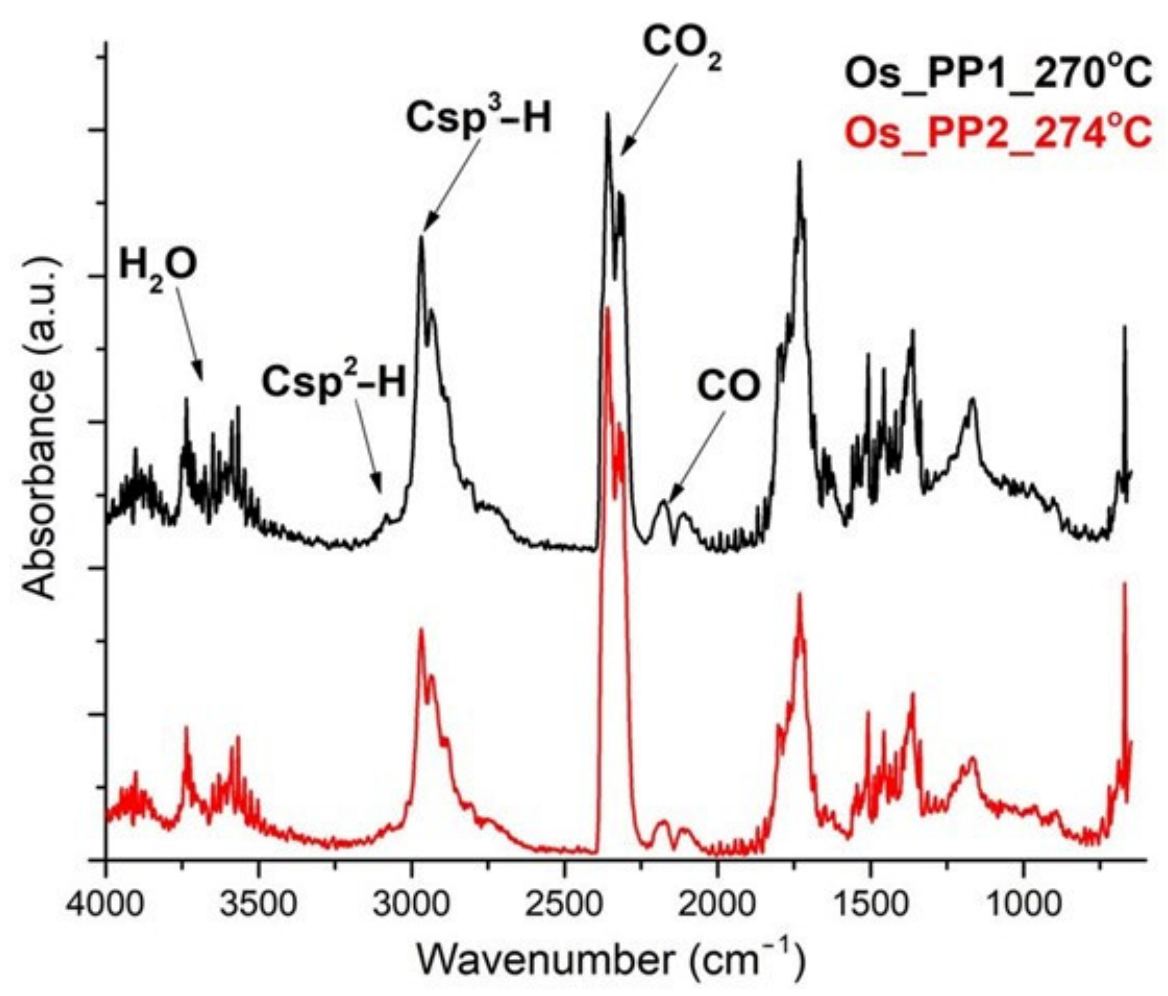

Figure 12. FTIR spectra of evolved gases at $270{ }^{\circ} \mathrm{C}$ for Os-PP1, and at $274{ }^{\circ} \mathrm{C}$ for Os-PP2.

This indicates that the degradation of the composite membranes started as a complex process, in which both decomposition and oxidation of the polymeric matrix took place simultaneously.

The bidimensional temperature/wavenumber projection of the 3D FTIR chromatogram for Os-PP1 (Figure 13a) can be used to visualize, at a glance, the temperature intervals where decomposition or oxidations took place. Figure 13a marks the areas where the vibration frequencies characteristic for water, $\mathrm{CO}_{2}, \mathrm{CO}$, and hydrocarbons appeared, to highlight the elimination in time. The green, vertical line at $2964 \mathrm{~cm}^{-1}$ represents the release profile with temperature of the hydrocarbons. It was observed that the elimination profile of hydrocarbons by decomposition was different between Os-PP1 and Os-PP2. It can be stated that the differences between $\mathrm{T}_{10}-\mathrm{T}_{50}$ (Table 2) can be the subject of the study. Thus, in the case of Os-PP1, a more accentuated decomposition of polypropylene (PP) took place, while in the case of Os-PP2, this decomposition was lower in the $200-300{ }^{\circ} \mathrm{C}$ temperature interval.

\subsection{Reduction of P-Nitrophenol with Molecular Hydrogen with Osmium Nanoparticles-Polypropylene Hollow Fibers Composite Membranes}

The reduction of nitroderivatives is a reaction of ennobling of some intermediate compounds for multiple products of biological interest, and the nitrophenols are the most intensively studied target substances both for the accessibility of analytical monitoring and for their biomedical importance and impact on environment [24,47,48]. These two arguments are the basis for determination of the process performance of composite membranes based on osmium nanoparticles-polypropylene hollow fibers Os-PP1 and Os-PP2 in the reduction reaction of $p$-nitrophenol from lower aliphatic alcohol solutions with molecular hydrogen. 


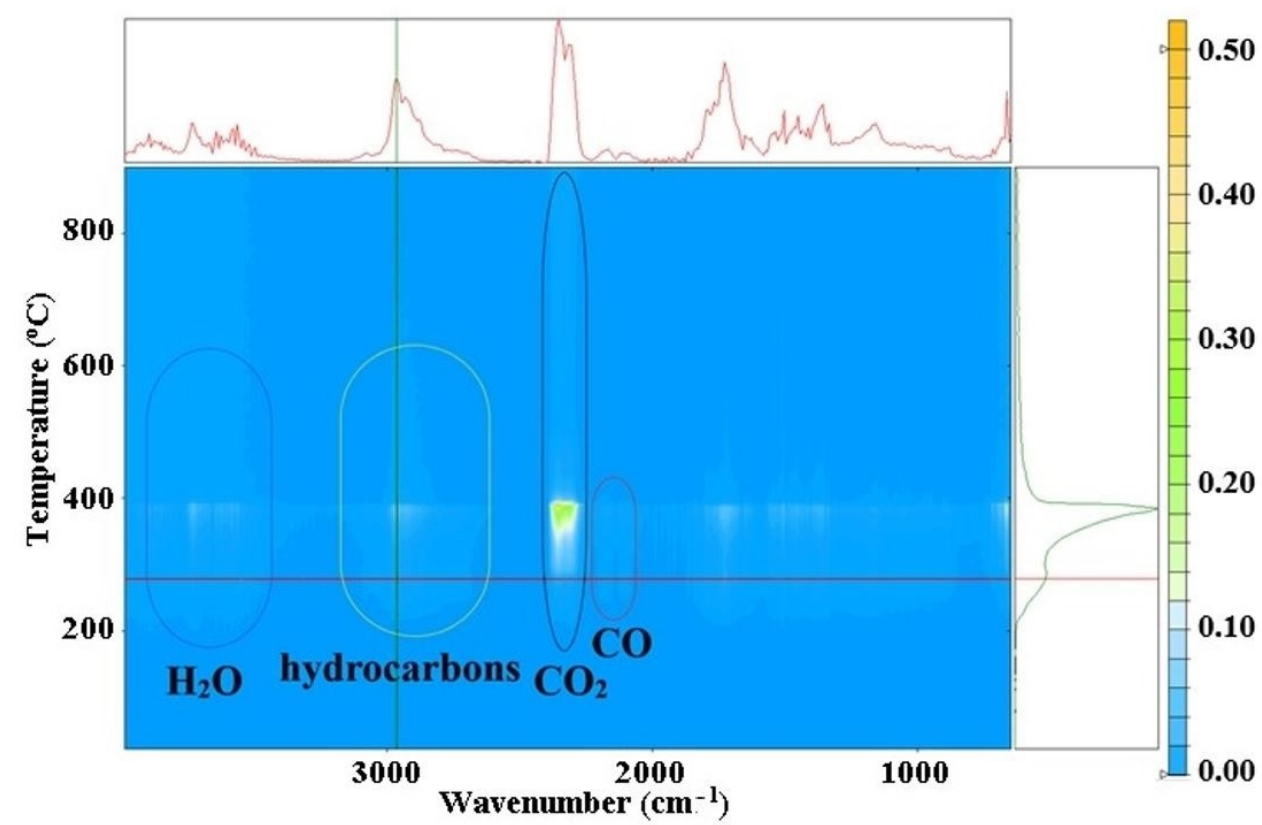

(a)

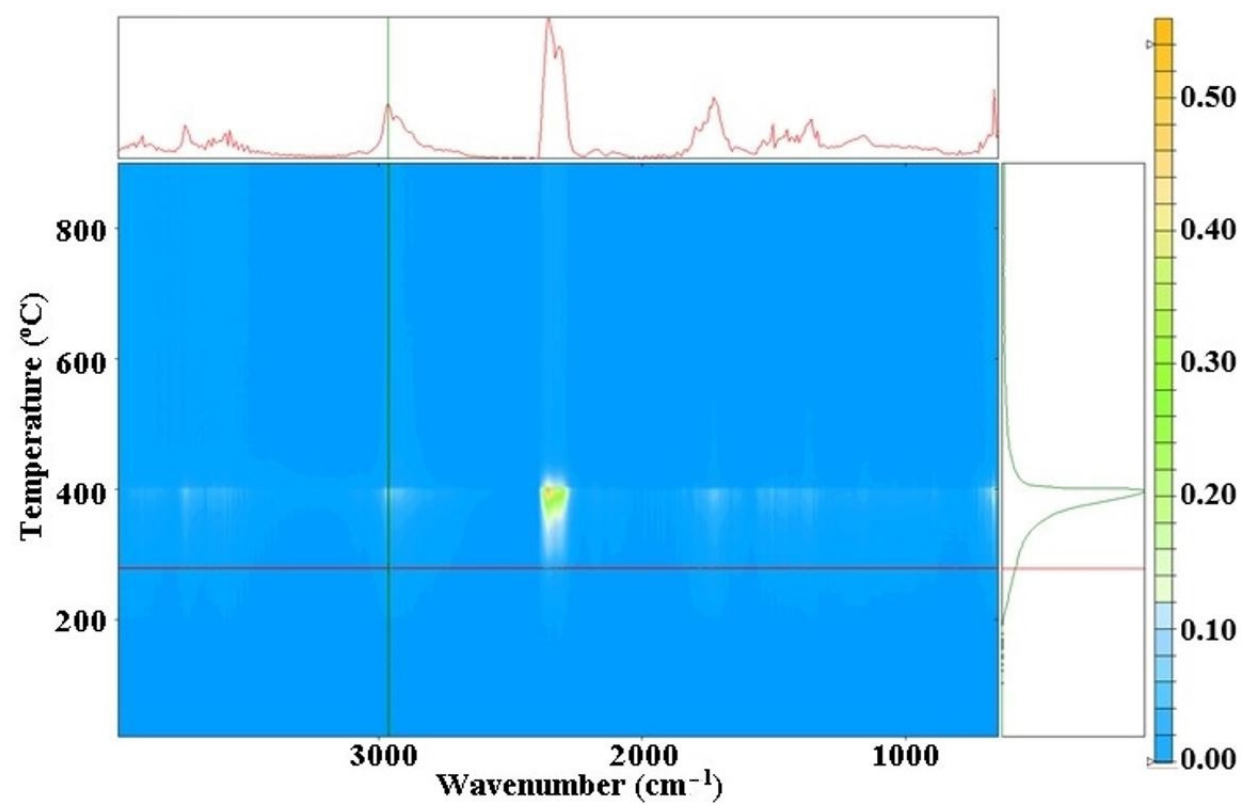

(b)

Figure 13. Bidimensional temperature/wavenumber projection for the 3D FTIR plot, indicating the temperature interval where various compounds were found in evolved gases from the thermal analysis of composite membranes: Os-PP1 (a); and Os-PP2 (b).

For the comparison of the results, a composite membrane of osmium nanoparticlespolypropylene hollow fibers Os-PP0 was tested, recently reported for reduction of 5nitrobenzimidazole [64].

The reduction process was carried out according to the chemical reactions (4) and (5), but the equilibria (6) and (7) must also be considered, in which either the hydration water of osmium nanoparticles or the one resulting from reaction can participate.

$$
\begin{gathered}
\mathrm{R}-\mathrm{OH}+\mathrm{R}-\mathrm{OH} \rightleftarrows \mathrm{R}-\mathrm{O}^{-}+\mathrm{R}-\mathrm{OH}_{2}^{+} \\
\mathrm{HO}-\mathrm{C}_{6} \mathrm{H}_{4}-\mathrm{NO}_{2}+3 \mathrm{H} 2 \rightleftarrows \mathrm{HO}-\mathrm{C}_{6} \mathrm{H}_{4}-\mathrm{NH}_{2}+2 \mathrm{H}_{2} \mathrm{O}
\end{gathered}
$$




$$
\begin{gathered}
\mathrm{HOH}+\mathrm{HOH} \rightleftarrows \mathrm{HO}+\mathrm{H}_{3} \mathrm{O}^{+} \\
\mathrm{H}_{3} \mathrm{O}^{+}+\mathrm{e}^{-} \rightleftarrows 1 / 2 \mathrm{H}_{2}+\mathrm{H}_{2} \mathrm{O}
\end{gathered}
$$

The reduction of nitro derivatives with osmium compounds is very well known $[32,33,66]$, but the study of this process on osmium nanoparticles with hydrogen gas is much less approached, the in-situ generation of molecular hydrogen especially with sodium borohydride being preferred $[67,68]$.

At the same time, the choice of the alcoholic reaction medium is sustained due to the low solubility of hydrogen gas in the aqueous medium [69].

The obtained results highlight the influence of the membrane type (Os-PP0, OsPP1 and Os-PP2) (Figure 14), concentration of $p$-nitrophenol solution (Figure 15), and nature of the primary alcohol (Figure 16$)$ over the conversion $(\eta \%)$, when reducing $p$ nitrophenol from alcoholic solution for the composite membranes of osmium nanoparticlespolypropylene hollow fibers (Os-PP).

$$
\eta \text { Os-PP0 }<\eta \text { Os-PP1 }<\eta \text { Os-PP2 }
$$

In the membrane contactor (Figure 4), at a temperature of $25^{\circ} \mathrm{C}, 10 \mathrm{~L}$ of $1 \mathrm{~g} / \mathrm{L}$ solution $p$-nitrophenol in $t$-butanol solution was introduced, which was recirculated at a flow rate of $0.100 \mathrm{~L} / \mathrm{min}$ through the outside of the composite membranes of nanoparticles of osmiumpolypropylene hollow fibers, while molecular hydrogen was continuously introduced into the system at a flow rate of $1 \mathrm{~L} / \mathrm{min}$ through the membranes. The experiments performed for each type of composite membrane (Os-PP0, Os-PP1, and Os-PP2) for six hours showed that the evolution of hydrogenation was slow at the beginning of the operation interval, and the conversion value $(\eta \%)$ reached 75\% (Os-PP0), 83\% (Os-PP1), and 87\% (Os-PP2) at six hours (Figure 14).

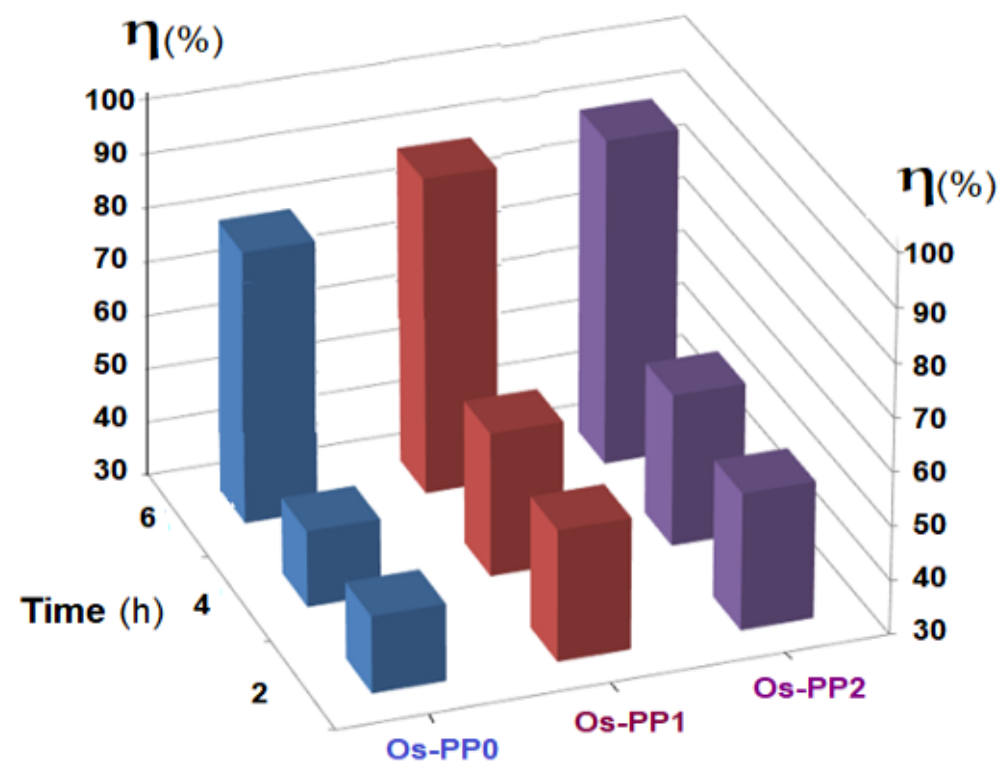

\section{Membranes}

Figure 14. Influence of membrane type (Os-PP0, Os-PP1 and Os-PP2) on the conversion ( $\eta$ \%), to the reduction of $p$-nitrophenol in tert-butyl alcohol solution as a function of operating time (h). 


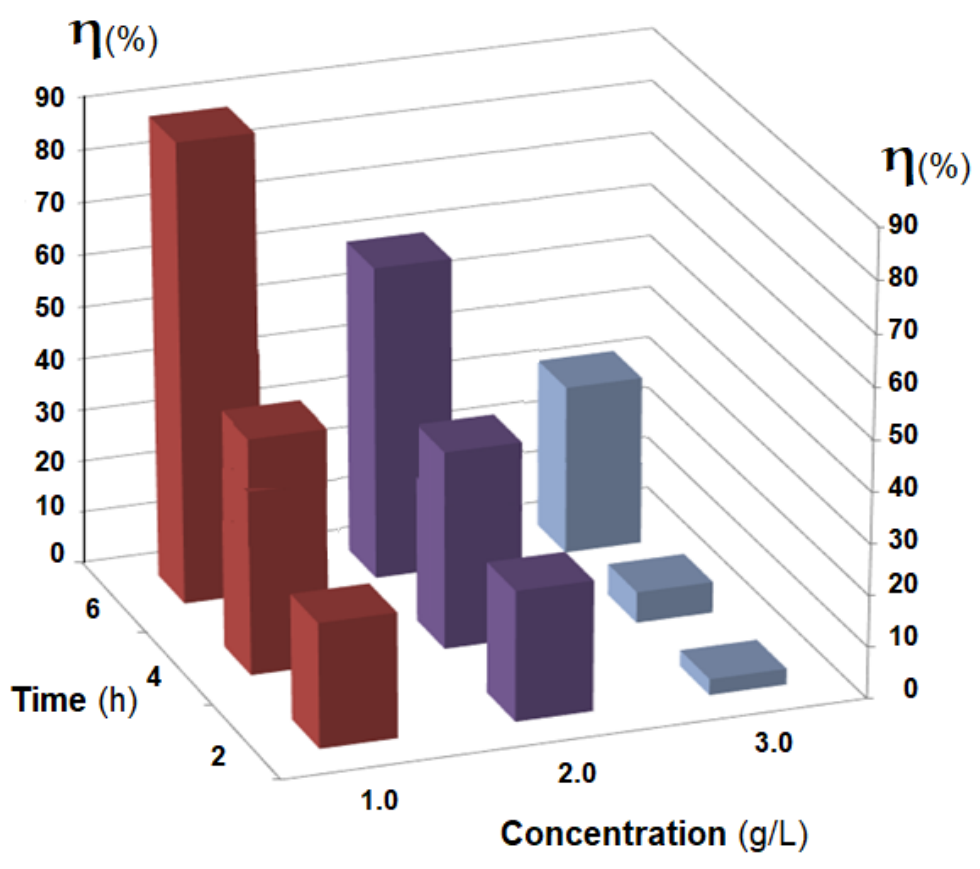

Figure 15. The influence, as a function of operating time $(\mathrm{h})$, of $p$-nitrophenol concentration $(\mathrm{g} / \mathrm{L})$ on conversion $(\eta \%)$ to reduction of $p$-nitrophenol in tert-butyl alcohol solution.

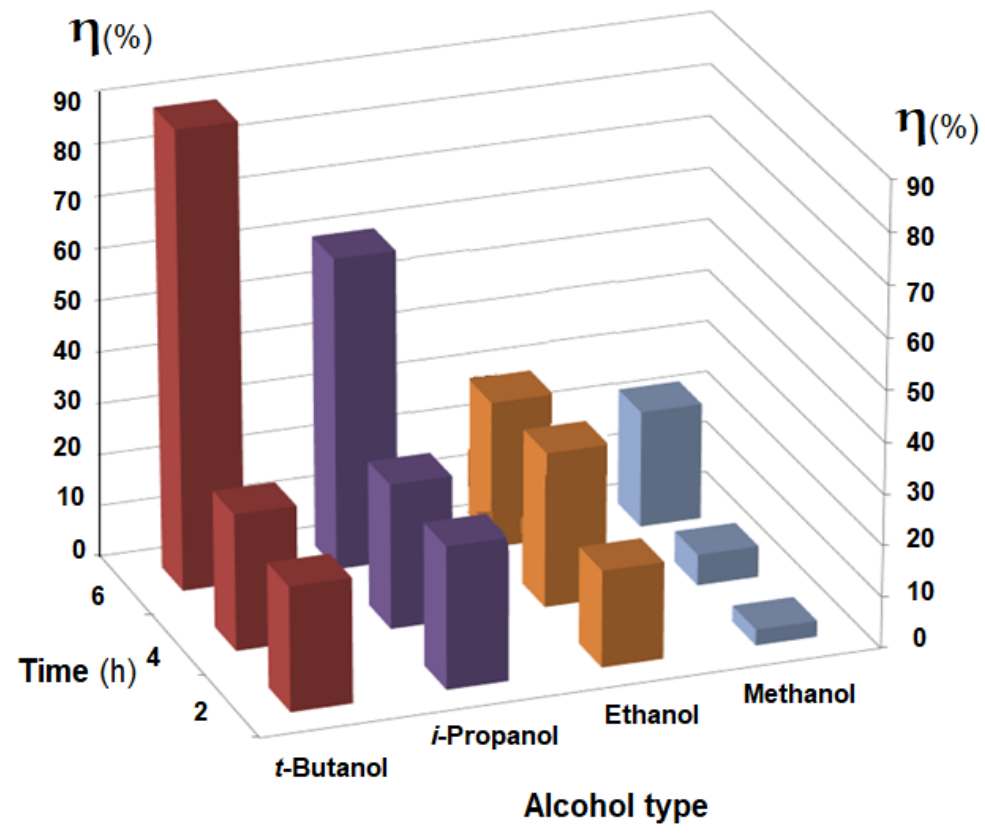

Figure 16. The influence of the nature of the primary alcohol ( $t$-butanol, $i$-propanol, ethanol, or methanol) on the conversion $(\eta \%)$ to the reduction of $p$-nitrophenol in the solution, depending on the operating time $(\mathrm{h})$.

The conversion values are directly related to the osmium concentration at the membrane surface (Table 1) increasing in the following order:

Using the most performant composite membrane obtained (Os-PP2), the hydrogenation of $p$-nitrophenol was then followed, in concentrations of 1.0-3.0 g/L, under the same experimental conditions (Figure 15). The conversion of $p$-nitrophenol ( $\eta \%$ ) decreased with increasing concentration of $p$-nitrophenol in $t$-butanol solution. The results of the conversion $(\eta \%)$ at six hours of operation varies from $85 \%$ for the $1.0 \mathrm{~g} / \mathrm{L}$ solution, $56 \%$ for the $2.0 \mathrm{~g} / \mathrm{L}$ solution, and $28 \%$ for the $3.0 \mathrm{~g} / \mathrm{L}$ solution. For a high conversion, it will be necessary to either operate with dilute solutions or increase the working time. 
The type of alcohol, used as solvent, significantly influenced the conversion of $p$ nitrophenol for the tested membrane (Os-PP2) (Figure 16). The results obtained for a p-nitrophenol solution of $1.0 \mathrm{~g} / \mathrm{L}$, under the previous experimental conditions, at six hours of operation, showed a conversion ( $\eta$ \%) of $85 \%$ for $t$-butanol, $57 \%$ for $i$-propanol, $24 \%$ for ethanol, and $19 \%$ for methanol.

The study performed on the reduction reaction of $p$-nitrophenol from solutions of lower aliphatic alcohols, with molecular hydrogen, on composite membranes of osmium nanoparticles-polypropylene hollow fibers (Os-PP) allowed the establishment of the following parameters:

- Composite membrane of osmium nanoparticles-polypropylene hollow fibers: Os-PP2 ( $7.63 \%$ atomic bone on the surface),

- Operating time: six hours,

- Concentration of $p$-nitrophenol in $t$-butanol: $1 \mathrm{~g} / \mathrm{L}$,

- Primary alcohol: $t$-butanol.

\subsection{Oxidation of 10-Undecylenic Acid on Osmium Nanoparticles-Polypropylene Hollow Fiber Composite Membranes Using Molecular Oxygen}

The 10-undecylenic acid is an accessible substance with multiple industrial applications, in sports biomedicine but also as membrane material (spacer). The oxidation of this compound is of particular interest for technical applications, but especially biomedical, because its properties can be altered when the athletes who use it bring it into contact with various powders (talc, zinc oxide, titanium oxide) used for adhesion and solar UV rays [70-73].

In the present case, the oxidation of 10-undecylenic acid was achieved from alcoholic solution on osmium nanoparticles-polypropylene hollow fibers composite membranes, using molecular oxygen (Figure 17). The reaction of oxidation performed in the installation depicted in Figure 4 used an alcoholic solution (ethanol, $i$-propanol, and $t$-butanol) of 10-undecylenic acid of concentration of 1.0,3.0, and $5.0 \mathrm{~g} / \mathrm{L}$ at a volume of $10 \mathrm{~L}$ and a recirculation flow of $0.100 \mathrm{~L} / \mathrm{min}$, through the contactor membrane system, through the outside of the osmium-polypropylene hollow fiber composite membranes (Os-PP2). Molecular oxygen was introduced through membranes, at a flow rate of $1 \mathrm{~L} /$ minute, a temperature of $25^{\circ} \mathrm{C}$, and a pressure of $1 \mathrm{~atm}$. The operating time was set at a maximum of five hours.



Figure 17. Scheme of molecular oxygen oxidation of 10-undecylenic acid on osmium nanoparticles-polypropylene hollow fibers (Os-PP2) composite membrane.

Figure 18 shows the results of 10-undecylenic acid oxidation, depending on time and nature of the primary alcohol used. The conversion ( $\eta$ \%) of 10 -undecylenic grew from $48 \%$ to $97 \%$ during five hours for $t$-butanol, and from $60 \%$ to $82 \%$ for ethanol. The conversion for $i$-propanol fell between the other two solvents. The conversion began more abruptly for the solvent with lower molecular weight, but towards the end of the operation, the order of conversion in the presence of the three alcohols was reversed. Most likely, this aspect of the conversion was determined by the two stages of the process: double-bond oxidation followed by alcoholysis. 




Figure 18. Conversion ( $\eta \%)$, as a function of time, of 10-undecylenic acid after molecular oxygen oxidation on the osmium nanoparticles-polypropylene hollow fibers (Os-PP2) composite membrane, for selected primary alcohols.

To study the influence of 10-undecylenic acid concentration in the alcohol solution as a function of time, the solvent that showed the maximum conversion at five hours of operation, $t$-butanol, was chosen (Figure 19).

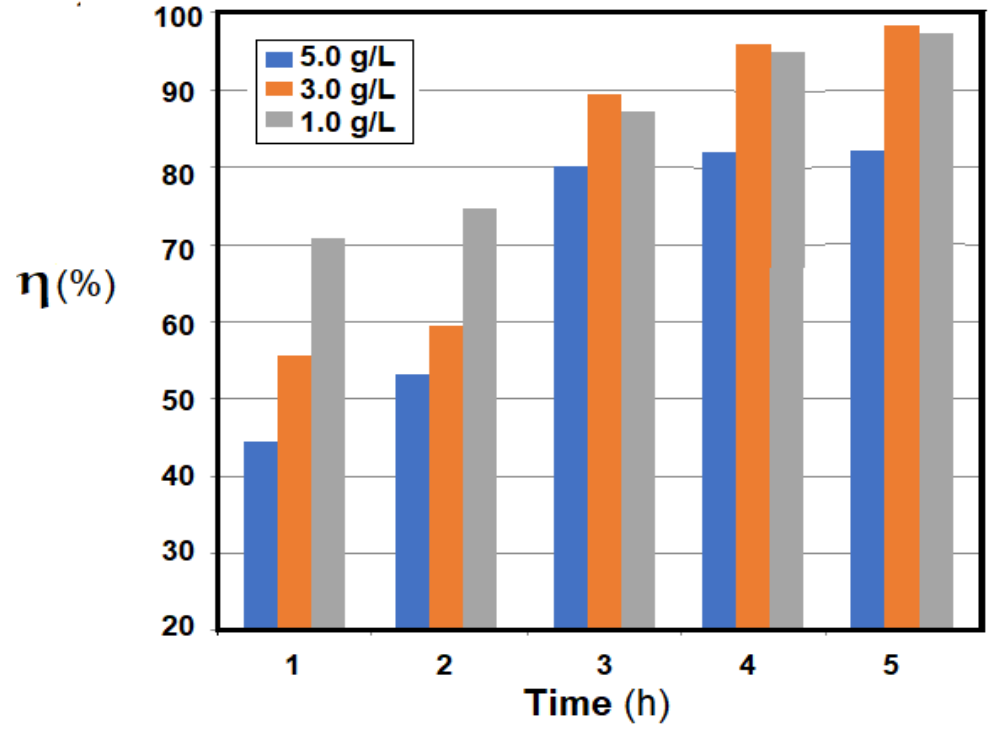

Figure 19. Conversion ( $\eta \%)$, as a function of time, of 10-undecylenic acid of variable concentration, after molecular oxygen oxidation on the osmium nanoparticles-polypropylene hollow fibers (Os-PP2) composite membrane.

The conversion $(\eta \%)$ as a function of time for 10-undecylenic acid of variable concentration $(1.0,3.0$ and $5.0 \mathrm{~g} / \mathrm{L})$ at oxidation with molecular oxygen on the osmium nanoparticles-polypropylene hollow fibers (Os-PP2) composite membrane showed that at high concentrations, the conversion was lower at the beginning of oxidation, but during the process, the conversions approached each other, reaching values of over $80 \%$ for the entire chosen concentration range after five hours.

The oxidation of 10-undecylenic acid follows a probable three-stage mechanism:

1. Through the intervention of osmium nanoparticles, oxygen is physically-chemically linked to the double-bond; 
2. The alcohol (mostly in the environment) produces the alcoholysis of the osmic acid ester producing a variety of reaction products (the reaction was modified in manuscript according to these data); and

3. The products are released into the environment.

The complex qualitative composition of the reaction mass, determined by chromatographic separation and FTIR spectroscopy identification of the components, showed that the glycolic compound obtained was majority $\left(R_{1}, R_{2}\right.$, and $R_{3}$ being the hydrogen atoms), but also alkylated compounds with ethyl, propyl, and butyl (in various positions) were detected (see Table S1).

A very special aspect of our research is the problem of loss of osmium and/or osmium nanoparticles in the reaction medium. Beyond the high economic value of osmium, the toxicity of its compounds (especially osmium tetroxide) requires both operational safety measures and rigorous control of operations. For the research carried out in this study, osmium nanoparticles were permanently operated in reaction space outside the fibers. To avoid the loss of osmium nanoparticles from the reaction compartment, the alcoholic reaction mass was extracted from the membrane module by vacuum suction inside the polypropylene hollow fiber membranes. At the same time, the reaction compartment was subjected to a nitrogen gas flow after each reduction operation (hydrogenation) before the recovery of the reaction mass (See Figure S7). After the oxidation process, the reaction compartment underwent three stages of tartar: with nitrogen gas to remove residual oxygen, with hydrogen (at least two hours to reduce any traces of osmium tetroxides), and then with nitrogen to remove residual hydrogen. The filtration characteristics of polypropylene hollow fiber membranes [56-64] ensured the complete retention of osmium nanoparticles in the reaction compartment which could be followed by established analytical techniques [74-78].

\section{Conclusions}

This paper presented the preparation and characterization of a composite membrane of active metal nanoparticle-polymer support type, based on osmium nanoparticles obtained in situ on a polypropylene hollow fiber membrane. The osmium nanoparticles were generated from a solution of osmium tetroxide of different concentrations in tertbutyl alcohol, by reduction with molecular hydrogen, in a contactor with polypropylene membrane.

The osmium nanoparticles-polypropylene hollow fibers (Os-PP) composite membranes were characterized morphologically and structurally by scanning electron microscopy (SEM), thermal analysis, surface analysis, and Fourier transform infrared (FTIR) spectroscopy.

The performance of osmium nanoparticles-polypropylene hollow fibers (Os-PP2) composite membranes was tested during the processes of reduction or oxidation of two compounds of technological and biomedical interests ( $p$-nitrophenol and 10-undecylenic acid) from lower saturated alcohol solutions.

The results obtained showed that the reduction of $p$-nitrophenol with molecular hydrogen on composite membranes based on osmium nanoparticles-polypropylene hollow fibers (Os-PP) can be performed with conversions of about $90 \%$, under the following conditions:

- Composite membrane of osmium nanoparticles-polypropylene hollow fibers: Os-PP2 ( $7.63 \%$ atomic Os on the surface),

- Operating time: six hours,

- The concentration $p$-nitrophenol in $t$-butanol: $1 \mathrm{~g} / \mathrm{L}$,

- Primary alcohol: $t$-butanol.

Oxidation of 10-undecylenic acid with molecular oxygen on composite membranes of osmium nanoparticles-polypropylene hollow fibers (Os-PP) took place with conversions of over $80 \%$ of solutions in $t$-butanol of concentration $1-5 \mathrm{~g} / \mathrm{L}$, at an operating time of five 
hours. The composition of the reaction mass to the oxidation of 10-undecylenic acid is complex and requires further studies.

To avoid the loss of osmium nanoparticles from the reaction compartment outside the fibers of the membrane module, the alcoholic reaction mass was extracted from the membrane module by vacuum suction inside the polypropylene hollow fiber membranes.

Supplementary Materials: The following are available online at https:/ / www.mdpi.com/article/10 $.3390 /$ nano11102526/s1, Figure S1: The appearances of crystallized metallic osmium and osmium powder, Figure S2: Images with the solution of osmium tetroxide in tert-butanol, the obtained metallic osmium and the osmium powder retained on a microporous membrane, Figure S3: Images with the bottle in which the osmium tetroxide was kept tightly sealed and the osmium powder obtained, Figure S4: Scanning electron microscopy (SEM) images of polypropylene hollow fiber membrane support, Figure S5: X-ray diffraction diagrams for polypropylene hollow fiber membrane dust, Figure S6: Scanning electron microscopy (SEM) and energy dispersive spectroscopy analysis (EDAX) on polypropylene hollow fiber membrane support, Figure S7: The specific safety operations on reactional processes and the obtained membranes, Table S1: The composition of the reaction mass to the oxidation with molecular oxygen of 10-undecylenic acid on osmium-polypropylene hollow fiber composite membranes.

Author Contributions: Conceptualization, G.N., F.M.P., V.-A.G. and P.C.A.; methodology, C.B., P.C.A., A.R.G., V.-A.G. and A.C.N.; validation, G.N., C.B. and A.R.G.; formal analysis, A.R.G., A.P., F.M.P., V.-A.G., S.-K.T., P.C.A. and A.C.N.; investigation, A.C.N., G.N., O.O., V.-A.G., A.P., S.-K.T., P.C.A., F.M.P. and A.R.G.; resources, G.N., C.B. and A.C.N.; data curation, A.P. and V.-A.G.; writingoriginal draft preparation, A.C.N., O.O., V.-A.G., F.M.P., P.C.A. and A.R.G.; writing-review and editing, V.-A.G.; supervision, G.N., C.B. and A.C.N. All authors have read and agreed to the published version of the manuscript.

Funding: The authors acknowledge the support from a grant from the Romanian National Authority for Scientific Research and Innovation, CCCDI-UEFISCDI, project number Nucleus Project PN 19 060204 .

Acknowledgments: The authors gratefully acknowledge the valuable help and friendly assistance of Roxana Truşcă in performing the microscopy analysis, and Anton Ficai for courtesy and unrestricted access provided to the Food Safety Research Platform.

Conflicts of Interest: The authors declare no conflict of interest.

\section{References}

1. Liao, Z.; Zhu, J.; Li, X.; Van der Bruggen, B. Regulating composition and structure of nanofillers in thin film nanocomposite (TFN) membranes for enhanced separation performance: A critical review. Sep. Purif. Technol. 2021, 266, 118567. [CrossRef]

2. Zhu, J.; Hou, J.; Uliana, A.; Zhang, Y.; Tian, M.; Van der Bruggen, B. The rapid emergence of two-dimensional nanomaterials for high-performance separation membranes. J. Mater. Chem. A 2018, 6, 3773-3792. [CrossRef]

3. Abdelsamad, A.M.A.; Khalil, A.S.G.; Ulbricht, M. Influence of controlled functionalization of mesoporous silica nanoparticles as tailored fillers for thin-film nanocomposite membranes on desalination performance. J. Membr. Sci. 2018, 563, 149-161. [CrossRef]

4. Ang, M.B.M.Y.; Pereira, J.M.; Trilles, C.A.; Aquino, R.R.; Huang, S.-H.; Lee, K.-R.; Lai, J.-Y. Performance and antifouling behavior of thin-film nanocomposite nanofiltration membranes with embedded silica spheres. Sep. Purif. Technol. 2019, 210, 521-529. [CrossRef]

5. Lai, G.S.; Lau, W.J.; Goh, P.S.; Ismail, A.F.; Tan, Y.H.; Chong, C.Y.; Krause-Rehberg, R.; Awad, S. Tailor-made thin film nanocomposite membrane incorporated with graphene oxide using novel interfacial polymerization technique for enhanced water separation. Chem. Eng. J. 2018, 344, 524-534. [CrossRef]

6. Firouzjaei, M.D.; Shamsabadi, A.A.; Aktij, S.A.; Seyedfour, S.F.; Sharifian Gh, M.; Rahimpour, A.; Esfahani, M.R.; Ulbricht, M.; Soroush, M. Exploiting synergetic effects of graphene oxide and a silver-based metal-organic M.R.; framework to enhance antifouling and anti-biofouling properties of thin-film nanocomposite membranes. ACS Appl. Mater. Interfaces 2018, 10, 4296742978. [CrossRef]

7. Zhang, A.; Zhang, Y.; Pan, G.; Xu, J.; Yan, H.; Liu, Y. In situ formation of copper nanoparticles in carboxylated chitosan layer: Preparation and characterization of surface modified TFC membrane with protein fouling resistance and long-lasting antibacterial properties. Sep. Purif. Technol. 2017, 176, 164-172. [CrossRef]

8. Upadhyaya, L.; Semsarilar, M.; Quemener, D.; Fernández-Pacheco, R.; Martinez, G.; Coelhoso, I.M.; Nunes, S.P.; Crespo, J.G.; Mallada, R.; Portugal, C.A.M. Block Copolymer-Based Magnetic Mixed Matrix Membranes-Effect of Magnetic Field on Protein Permeation and Membrane Fouling. Membranes 2021, 11, 105. [CrossRef] 
9. Kuroda, K.; Ishida, T.; Haruta, M. Reduction of 4-nitrophenol to 4-aminophenolover Au nanoparticles deposited on PMMA. J. Mol. Catal. A Chem. 2009, 298, 7-11. [CrossRef]

10. Koga, H.; Kitaoka, T. One-step synthesis of gold nanocatalysts on a micro-structured paper matrix for the reduction of 4nitrophenol. Chem. Eng. J. 2011, 168, 420-425. [CrossRef]

11. Dong, Z.; Le, X.; Dong, C.; Zhang, W.; Li, X.; Ma, J. Ni@Pd core-shell nanoparticles modified fibrous silica nanospheres as highly efficient and recoverable catalyst for reduction of 4-nitrophenol and hydrodechlorination of 4-chlorophenol. Appl. Catal. B Environ. 2015, 162, 372-380. [CrossRef]

12. Woo, S.T.; Yun, T.; Kwak, S.-Y. Fouling-resistant microfiltration membrane modified with magnetite nanoparticles by reversible conjunction. Sep. Pur. Technol. 2018, 202, 299-306. [CrossRef]

13. Ghaemi, N.; Madaeni, S.S.; Daraei, P.; Rajabi, H.; Zinadini, S.; Alizadeh, A.; Heydari, R.; Beygzadeh, M.; Ghouzivand, S. Polyethersulfone membrane enhanced with iron oxide nanoparticles for copper removal from water: Application of new functionalized Fe3O4 nanoparticles. Chem. Eng. J. 2015, 263, 101-112. [CrossRef]

14. Agbaje, T.A.; Al-Gharabli, S.; Mavukkandy, M.O.; Kujawa, J.; Arafat, H.A. PVDF/magnetite blend membranes for enhanced flux and salt rejection in membrane distillation. Desalination 2018, 436, 69-80. [CrossRef]

15. Harish, S.; Mathiyarasu, J.; Phani, K.L.N.; Yegnaraman, V. Synthesis of conducting polymer supported Pd nanoparticles in aqueous medium and catalytic activity towards 4-nitrophenol reduction. Catal. Lett. 2009, 128, 197. [CrossRef]

16. Khalil, A.M.; Georgiadou, V.; Guerrouache, M.; Mahouche-Chergui, S.; Dendrinou-Samara, C.; Chehimi, M.M.; Carbonnier, B. Gold- decorated polymeric monoliths: In-situ vs. ex-situ immobilization strategies and flow through catalytic applications towards nitrophenols reduction. Polymer 2015, 77, 218-226. [CrossRef]

17. Macanás, J.; Ouyang, L.; Bruening, M.L.; Muñoz, M.; Remigy, J.-C.; Lahitte, J.-F. Development of polymeric hollow fiber membranes containing catalytic metal nanoparticles. Catal. Today 2010, 156, 181-186. [CrossRef]

18. Wang, C.; Yin, J.; Han, S.; Jiao, T.; Bai, Z.; Zhou, J.; Zhang, L.; Peng, Q. Preparation of Palladium Nanoparticles Decorated Polyethyleneimine/Polycaprolactone Composite Fibers Constructed by Electrospinning with Highly Efficient and Recyclable Catalytic Performances. Catalysts 2019, 9, 559. [CrossRef]

19. Rajakumaran, R.; Kumar, M.; Chetty, R. Morphological effect of ZnO nanostructures on desalination performance and antibacterial activity of thin-film nanocomposite (TFN) membrane. Desalination 2020,495, 114673. [CrossRef]

20. Wang, J.; Wang, Y.; Zhu, J.; Zhang, Y.; Liu, J.; van der Bruggen, B. Construction of $\mathrm{TiO}_{2} @$ graphene oxide incorporated antifouling nanofiltration membrane with elevated filtration performance. J. Membr. Sci. 2017, 533, 279-288. [CrossRef]

21. Liu, C.; Faria, A.F.; Ma, J.; Elimelech, M. Mitigation of biofilm development on thin film composite membranes functionalized with zwitterionic polymers and silver nanoparticles. Environ. Sci. Technol. 2017, 51, 182-191. [CrossRef]

22. Mehrabi, Z.; Taheri-Kafrani, A.; Asadnia, M.; Razmjou, A. Bienzymatic modification of polymeric membranes to mitigate biofouling. Sep. Purif. Technol. 2020, 237, 116464. [CrossRef]

23. Hradil, J.; Krystl, V.; Hrabanek, P.; Bernauer, B.; Kocirık, M. Heterogeneous membranes based on polymeric adsorbents for separation of small molecules. React. Funct. Polym. 2004, 61, 303-313. [CrossRef]

24. Yin, J.; Zhan, F.; Jiao, T.; Deng, H.; Zou, G.; Bai, Z.; Zhang, Q.; Peng, Q. Highly efficient catalytic performances of nitro compounds via hierarchical PdNPs-loaded MXene/polymer nanocomposites synthesized through electrospinning strategy for wastewater treatment. Chin. Chem. Lett. 2020, 31, 992-995. [CrossRef]

25. Wang, H.; Dong, Z.; Na, C. Hierarchical carbon nanotube membrane-supported gold nanoparticles for rapid catalytic reduction of p-nitrophenol. ACS Sustain. Chem. Eng. 2013, 1, 746-752. [CrossRef]

26. Wu, W.; Liu, G.; Liang, S.; Chen, Y.; Shen, L.; Zheng, H.; Yuan, R.; Hou, Y.; Wu, L. Efficient visible-light-induced photocatalytic reduction of 4-nitroaniline to p-phenylenediamine over nanocrystalline PbBi2Nb2O9. J. Catal. 2012, 290, 13-17. [CrossRef]

27. Le, X.; Dong, Z.; Li, X.; Zhang, W.; Le, M.; Ma, J. Fibrous nano-silica supported palladium nanoparticles: An efficient catalyst for the reduction of 4-nitrophenol and hydrodechlorination of 4-chlorophenol under mild conditions. Catal. Commun. 2015, 59, 21-25. [CrossRef]

28. Fang, Y.; Wang, E. Simple and direct synthesis of oxygenous carbon supported palladium nanoparticles with high catalytic activity. Nanoscale 2013, 5, 1843-1848. [CrossRef] [PubMed]

29. Bazhenov, S.D.; Bildyukevich, A.V.; Volkov, A.V. Gas-liquid hollow fiber membrane contactors for different applications. Fibers 2018, 6, 76. [CrossRef]

30. Sirkar, K.K.; Shanbhag, P.V.; Kovvali, A.S. Membrane in a Reactor: A Functional Perspective. Ind. Eng. Chem. Res. 1999, 38, 10, 3715-3737. [CrossRef]

31. de Pedro, Z.M.; Diaz, E.; Mohedano, A.F.; Casas, J.A.; Rodriguez, J. Compared activity and stability of Pd/Al2O3 and Pd/AC catalysts in 4-chlorophenol hydrodechlorination in different pH media. J. Appl. Catal. B Environ. 2011, 103, 128-135. [CrossRef]

32. Borja-Arco, E.; Castellanos, R.H.; Uribe-Godínez, J.; Altamirano-Gutiérrez, A.; Jiménez-Sandoval, O. Osmium-ruthenium carbonyl clusters as methanol tolerant electrocatalysts for oxygen reduction. J. Power Sources 2009, 188, 387-396. [CrossRef]

33. Bolitho, E.M.; Coverdale, J.P.C.; Bridgewater, H.E.; Clarkson, G.J.; Quinn, P.D.; Sanchez-Cano, C.; Sadler, P.J. Tracking Reactions of Asymmetric Organo-Osmium Transfer Hydrogenation Catalysts in Cancer Cells. Angew. Chem. Int. Ed. 2021, 60, 6462-6472. [CrossRef]

34. Adams, C.W.M.; Abdulla, Y.H.; Bayliss, O.B. Osmium tetroxide as a histochemical and histological reagent. Histochemie 1967, 9, 68-77. [CrossRef] 
35. Heller, A. Electron-conducting redox hydrogels: Design, characteristics and synthesis. Curr. Opin. Chem. Biol. 2006, 10, 664-672. [CrossRef]

36. Uribe-Godínez, J.; Castellanos, E.; Borja-Arco, R.H.; Altamirano-Gutiérrez, A.; Jiménez-Sandoval, O. Novel osmium-based electrocatalysts for oxygen reduction and hydrogen oxidation in acid conditions. J. Power Sources 2008, 177, 286-295. [CrossRef]

37. Zhang, H.; Liu, G.; Shi, L.; Ye, J. Single-Atom Catalysts: Emerging Multifunctional Materials in Heterogeneous Catalysis. Adv. Mat. 2018, 8, 1701343. [CrossRef]

38. Sharpless, K.B.; Amberg, W.; Bennani, Y.L.; Crispino, G.A.; Hartung, J.; Jeong, K.S.; Kwong, H.L.; Morikawa, K.; Wang, Z.M. The osmium-catalyzed asymmetric dihydroxylation: A new ligand class and a process improvement. J. Org. Chem. 1992, 57, 10, 2768-2771. [CrossRef]

39. Kolb, H.C.; Van Nieuwenhze, M.S.; Sharpless, K.B. Catalytic Asymmetric Dihydroxylation. Chem. Rev. 1994, 94, 8, $2483-2547$. [CrossRef]

40. Ma, L.; Abney, C.; Lin, W. Enantioselective catalysis with homochiral metal-organic frameworks. Chem. Soc. Rev. 2009, 38, 1248-1256. [CrossRef]

41. Yoon, T.P.; Jacobsen, E.N. Privileged Chiral Catalysts. Science 2003, 299, 1691-1693. [CrossRef]

42. Keith, L.; Telliard, W. Priority Pollutants. Environ. Sci. Technol. 1979, 13, 416-423. [CrossRef]

43. Nasrollahzadeh, M.; Jaleh, B.; Fakhri, P.; Zahraei, A.; Ghadery, E. Synthesis and catalytic activity of carbon supported copper nanoparticles for the synthesis of aryl nitriles and 1,2,3-triazoles. RSC Adv. 2015, 5, 2785-2793. [CrossRef]

44. Kristanti, R.A.; Toyama, T.; Hadibarata, T.; Tanaka, Y.; Mori, K. Sustainable removal of nitrophenols by rhizoremediation using four strains of bacteria and giant duckweed (Spirodela polyrhiza). Water. Air. Soil Pollut. 2014, 225, 1928-1937. [CrossRef]

45. Xiong, Z.; Zhang, H.; Zhang, W.; Lai, B.; Yao, G. Removal of Nitrophenols and their Derivatives by Chemical Redox: A Review. Chem. Eng. J. 2019, 359, 13-31. [CrossRef]

46. Jaleh, B.; Karami, S.; Sajjadi, M.; Feizi, B.; Azizian, S.; Nasrollahzadeh, M.; Varma, R.S. Laser-assisted preparation of Pd nanoparticles on carbon cloth for the degradation of environmental pollutants in aqueous medium. Chemosphere 2020, $246,125755$. [CrossRef]

47. Vassilev, D.; Petkova, N.; Tumbarski, Y.; Koleva, M.; Denev, P. Application of the principles of "green chemistry" for the synthesis of 10-undecylenic aliphatic esters with antimicrobial activity. J. Renew. Mater. 2020, 8, 675-686. [CrossRef]

48. Yasa, S.; Cheguru, S.; Krishnasamy, S.; Korlipara, P.; Rajak, A.; Penumarthy, V. Synthesis of 10-undecenoic acid based C22-dimer acid esters and their evaluation as potential lubricant basestocks. Ind. Crops Prod. 2017, 103, 141-151. [CrossRef]

49. Raku, T.; Kitagawa, M.; Shimakawa, H.; Tokiwa, Y. Enzymatic synthesis of hydrophilic undecylenic acid sugar esters and their biodegradability. Biotechnol. Lett. 2003, 25, 161-166. [CrossRef]

50. Cavalcante, I.M.; Rocha, N.R.D.C.; de Brito, D.H.A.; Schuller, A.P.D.; Camara Neto, J.F.; de Morais, S.M.; de Luna, F.M.T.; Schanz, M.T.G.F.; Maier, M.E.; Ricardo, N.M.P.S. Synthesis and characterization of novel polyol esters of undecylenic acid as ecofriendly lubricants. J. Am. Oil Chem Soc. 2019, 96, 75-82. [CrossRef]

51. Huerta-Ángeles, G.; Brandejsová, M.; Kopecká, K.; Ondreáš, F.; Medek, T.; Židek, O.; Kulhánek, J.; Vagnerová, H.; Velebný, V. Synthesis and Physicochemical Characterization of Undecylenic Acid Grafted to Hyaluronan for Encapsulation of Antioxidants and Chemical Crosslinking. Polymers 2020, 12, 35. [CrossRef]

52. Ghimpusan, M.; Nechifor, G.; Din, I.S.; Nechifor, A.C.; Passeri, P. Application of Hollow Fibre Membrane Bioreactor Instead of Granular Activated Carbon Filtration for Treatment of Wastewater from Car Dismantler Activity. Mat. Plast. 2016, 53, 578-584.

53. Din, I.S.; Cimbru, A.M.; Rikabi, A.A.K.K.; Tanczos, S.K.; Ticu (Cotorcea), S.; Nechifor, G. Iono-molecular Separation with Composite Membranes VI. Nitro-phenol separation through sulfonated polyether ether ketone on capillary polypropylene membranes. Rev. Chim. Buchar. 2018, 69, 1603-1607. [CrossRef]

54. Ghimpusan, M.; Nechifor, G.; Nechifor, A.C.; Dima, S.O.; Passeri, P. Case studies on the physical-chemical parameters' variation during three different purification approaches destined to treat wastewaters from food industry. J. Environ. Manag. 2017, 203, 811-816. [CrossRef] [PubMed]

55. Dimulescu, I.A.; Nechifor, A.C.; Bărdacă, C.; Oprea, O.; Paşcu, D.; Totu, E.E.; Albu, P.C.; Nechifor, G.; Bungău, S.G. Accessible Silver-Iron Oxide Nanoparticles as a Nanomaterial for Supported Liquid Membranes. Nanomaterials 2021, 11, 1204. [CrossRef]

56. Nechifor, A.C.; Cotorcea, S.; Bungău, C.; Albu, P.C.; Pașcu, D.; Oprea, O.; Grosu, A.R.; Pîrțac, A.; Nechifor, G. Removing of the Sulfur Compounds by Impregnated Polypropylene Fibers with Silver Nanoparticles-Cellulose Derivatives for Air Odor Correction. Membranes 2021, 11, 256. [CrossRef] [PubMed]

57. Grosu, A.R.; Nafliu, I.M.; Din, I.S.; Cimbru, A.M.; Nechifor, G. Neutralization with simultaneous separation of aluminum and copper ions from condensed water through capillary polypropylene and cellulose. UPB Sci. Bull. Ser. B Chem. Mater. Sci. 2020, 82, 25-34.

58. Nechifor, A.C.; Goran, A.; Grosu, V.-A.; Bungău, C.; Albu, P.C.; Grosu, A.R.; Oprea, O.; Păncescu, F.M.; Nechifor, G. Improving the Performance of Composite Hollow Fiber Membranes with Magnetic Field Generated Convection Application on $\mathrm{pH}$ Correction. Membranes 2021, 11, 445. [CrossRef]

59. Nechifor, A.C.; Pîrțac, A.; Albu, P.C.; Grosu, A.R.; Dumitru, F.; Dimulescu, I.A.; Oprea, O.; Pașcu, D.; Nechifor, G.; Bungău, S.G. Recuperative Amino Acids Separation through Cellulose Derivative Membranes with Microporous Polypropylene Fiber Matrix. Membranes 2021, 11, 429. [CrossRef] 
60. Diaconu, I.; Nechifor, G.; Nechifor, A.C.; Ruse, E.; Totu, E.E. Membranary techniques used at the separation of some phenolic compounds from aqueous media, UPB Scientific Bulletin. Ser. B Chem. Mater. Sci. 2009, 71, 39-46.

61. Szczepański, P.; Diaconu, I. Transport of p-nitrophenol through an agitated bulk liquid membrane. Sep. Sci. Technol. 2012, 47, 1725-1732. [CrossRef]

62. Koter, S.; Szczepański, P.; Mateescu, M.; Nechifor, G.; Badalau, L.; Koter, I. Modeling of the cadmium transport through a bulk liquid membrane. Sep. Purif. Technol. 2013, 107, 135-143. [CrossRef]

63. Diaconu, I.; Gîrdea, R.; Cristea, C.; Nechifor, G.; Ruse, E.; Totu, E.E. Removal and recovery of some phenolic pollutants using liquid membranes. Rom. Biotechnol. Lett. 2010, 15, 5702-5708.

64. Nechifor, A.C.; Goran, A.; Grosu, V.-A.; Pîrțac, A.; Albu, P.C.; Oprea, O.; Grosu, A.R.; Pașcu, D.; Păncescu, F.M.; Nechifor, G.; et al. Reactional Processes on Osmium-Polymeric Membranes for 5-Nitrobenzimidazole Reduction. Membranes 2021, 11, 633. [CrossRef] [PubMed]

65. Bărdacă Urducea, C.; Nechifor, A.C.; Dimulescu, I.A.; Oprea, O.; Nechifor, G.; Totu, E.E.; Isildak, I.; Albu, P.C.; Bungău, S.G. Control of Nanostructured Polysulfone Membrane Preparation by Phase Inversion Method. Nanomaterials 2020, 10, 2349. [CrossRef] [PubMed]

66. George, A.; Selvan, D.; Mandal, S. Catalytic Reduction of Toxic Nitroarenes in Aqueous Medium Using Worm-Like Rhodium Nanoparticles. Chem. Sel. 2017, 2, 9718-9721. [CrossRef]

67. Huang, T.; Fu, Y.; Peng, Q.; Yu, C.; Zhu, J.; Yu, A.; Wang, X. Catalytic hydrogenation of p-nitrophenol using a metal-free catalyst of porous crimped graphitic carbon nitride. Appl. Surf. Sci. 2019, 480, 888-895. [CrossRef]

68. Lu, H.; Yin, H.; Liu, Y.; Jiang, T.; Yu, L. Influence of support on catalytic activity of Ni catalysts in p-nitrophenol hydrogenation to p-aminophenol. Catal. Commun. 2008, 10, 313-316. [CrossRef]

69. Herskowitz, M.; Wisniak, J.; Skladman, L. Hydrogen solubility in organic liquids. J. Chem. Eng. Data 1983, 28, 164-166. [CrossRef]

70. Mionić Ebersold, M.; Petrović, M.; Fong, W.-K.; Bonvin, D.; Hofmann, H.; Milošević, I. Hexosomes with Undecylenic Acid Efficient against Candida Albicans. Nanomaterials 2018, 8, 91. [CrossRef]

71. Liakos, I.L.; Holban, A.M.; Carzino, R.; Lauciello, S.; Grumezescu, A.M. Electrospun Fiber Pads of Cellulose Acetate and Essential Oils with Antimicrobial Activity. Nanomaterials 2017, 7, 84. [CrossRef] [PubMed]

72. Shi, D.; Zhao, Y.; Yan, H.; Fu, H.; Shen, Y.; Lu, G.; Mei, H.; Qiu, Y.; Li, D.; Liu, W. Antifungal effects of undecylenic acid on the biofilm formation of Candida albicans. Int. J. Clin. Pharmacol. Ther. 2016, 54, 343-353. [CrossRef] [PubMed]

73. Petrović, M.; Bonvin, D.; Hofmann, H.; Mionić Ebersold, M. Fungicidal PMMA-Undecylenic Acid Composites. Int. J. Mol. Sci. 2018, 19, 184. [CrossRef] [PubMed]

74. Zanje, S.B.; Kokare, A.N.; Suryavanshi, V.J.; Waghmode, D.P.; Joshi, S.S.; Anuse, M.A. Development of a reliable analytical method for the precise extractive spectrophotometric determination of osmium(VIII) with 2-nitrobenzaldehydethiocarbohydrazone: Analysis of alloys and real sample. Spectrochim. Acta Part A Mol. Biomol. Spectrosc. 2016, 169, 223-229. [CrossRef] [PubMed]

75. Tabatabaee, M.; Bagheri, H.; Shahvazian, M. Application of thionine dye for highly sensitive and selective catalytic kinetic determination of osmium. Prog. Color Colorants Coat. 2010, 3, 33-40.

76. Tang, B.; Zhang, H.; Wang, Y. Flow injection kinetic spectrofluorimetric determination of trace amounts of osmium. Spectrochim. Acta Part A 2005, 61, 2239-2244. [CrossRef] [PubMed]

77. Suzuki, T.; Miyada, M.; Ohta, K.; Kaneco, S.; Mizuno, T. Determination of osmium in waste water by graphite furnace atomic absorption spectrometry. Mikrochim. Acta 1998, 129, 259-263. [CrossRef]

78. Gregoire, D.C. Sample introduction techniques for the determination of osmium isotope ratios by inductively coupled plasma mass spectrometry. Anal. Chem. 1990, 62, 141-146. [CrossRef] 